\title{
Effect of nitric oxide and inflammatory mediators on axonal transport
}

\author{
PhD Thesis \\ In partial fulfillment of the requirements for the degree \\ "Dr. rer. nat" \\ AT \\ THE GEORG-AUGUST UNIVERSITY GÖTTINGEN
}

\author{
Submitted by \\ Massimiliano Stagi \\ Born in \\ Montevarchi, Italy
}




\section{Declaration}

This thesis has been written independently and with no other sources and aids than stated.

Massimiliano Stagi

Date

Signature 


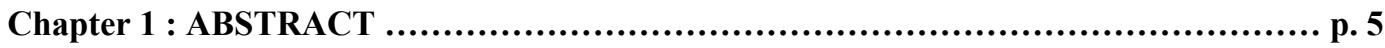

Chapter 2 : INTRODUCTION ................................................................. p.7

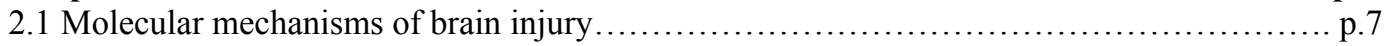

2.2 Microglial activation in the central nervous system........................................ p.

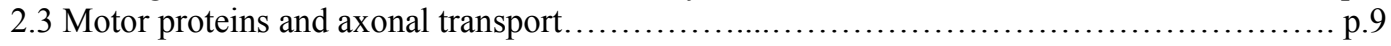

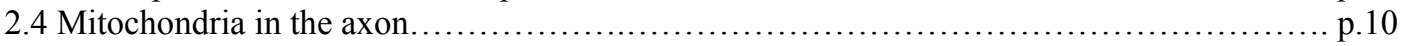

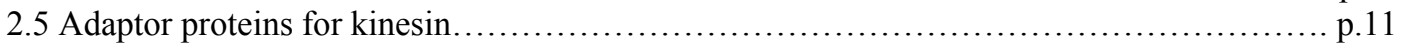

2.6 Technical approach to determine dynamics of axonal cargos ............................. p.11

2.7 Technical approach to determine interaction between motors and tubuline track............. p. 12

Chapter 3: MATERIAL AND METHODS.................................................... 14

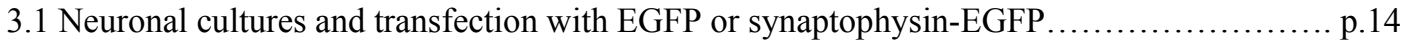

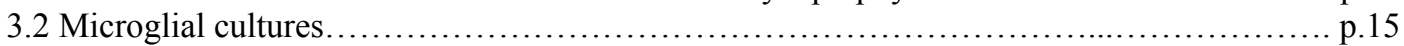

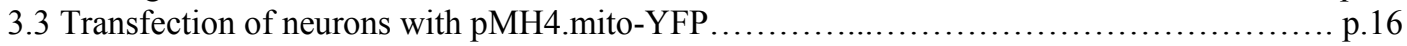

3.4 In vivo imaging and FRAP analysis...................................................... p. 16

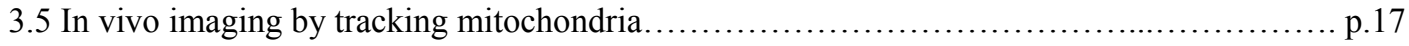

3.6 Detection of iNOS gene transcripts, TNF- $\alpha$ and NO release by microglia.................. p.18

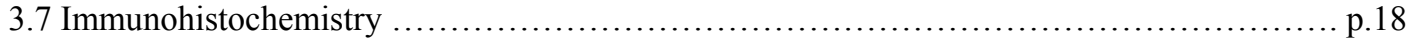

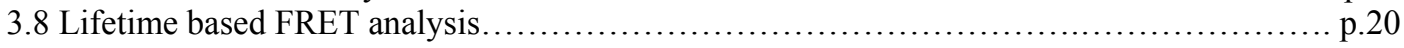

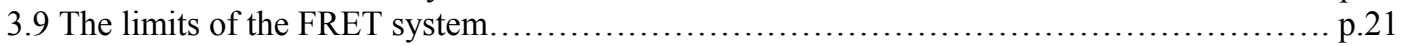

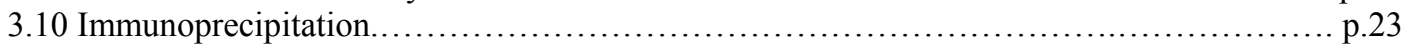

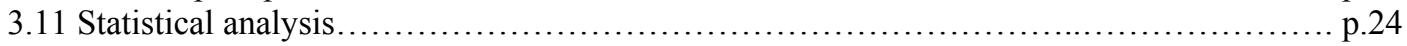

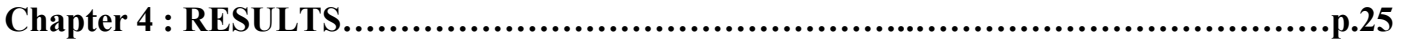

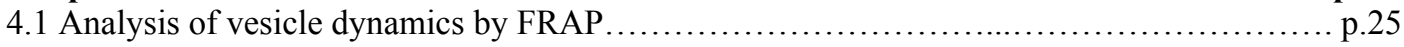

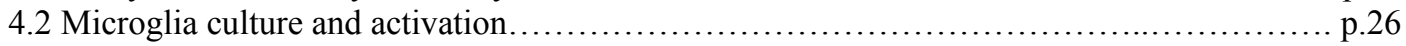

4.3 Mimicking the effect of nitric oxide (NO) and studing vesicle transport................... p.26

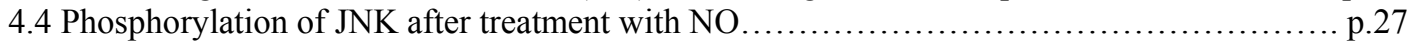

4.5 Effect of JNK-inhibitor on movement of synaptophysin-EGFP ......................... p. 28

4.6 Expression of TNF receptors on axons of cultured hippocampal neurons................... p. 28

4.7 Phosphorylated JNK in axons after treatment with TNF.................................. 28

4.8 Association between KIF5B, $\beta$-tubulin-III and JNK ................................ p.29

4.9 Dissociation of KIF5b from $\beta$-tubulin-III after TNF treatment in axons................... p.29

4.10 Involvement of JNK phosphorylation in dissociation of KIF5B and b-tubulin-III............ p.31

4.11 Inhibition of axonal mitochondrial transport by TNF via JNK phosphorylation.............. p.31

4.12 Inhibition of axonal synaptophysin transport by TNF via JNK phosphorylation............. p.32

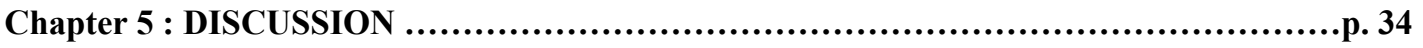

5.1 Analysis of directed movement with FRAP method.................................. p. 34

5.2 Effects of microglia $/ \mathrm{NO} / \mathrm{TNF}-\alpha$ on neurites............................................ p. 34

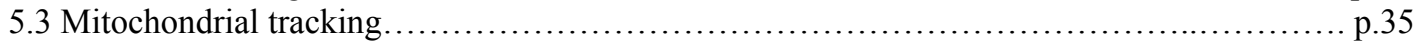

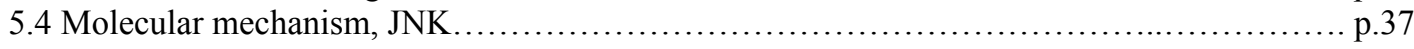

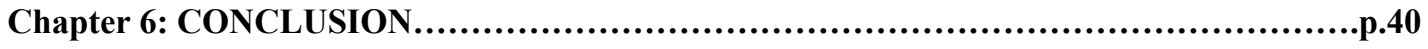

Chapter 7: REFERENCES......................................................................

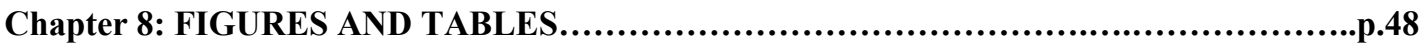

APPENDIX 1 : Abbreviations

APPENDIX 2: Published papers

APPENDIX 3: CV 
AKNOWLEDGMENTS 


\section{ABSTRACT}

Increased production of inflammatory cytokines such as tumor necrosis factor- $\alpha$ (TNF- $\alpha$ ) and reactive oxygen species by glia in the central nervous system (CNS) is a hallmark of a variety of inflammatory and degenerative brain diseases.

Axonal transport of mitochondria or synaptic vesicle precursors via the kinesin motor protein is essential to keep the integrity of the axon and synapse. Disturbance of axonal transport and accumulation of axonally transported organelles is an early sign of neuroinflammatory diseases such as multiple sclerosis, brain injury and Alzheimer's disease.

We studied whether axonal transport is compromised by acute exposure to inflammatory mediators produced by activated glia. We dissected the transport of the synaptic vesicle precursor proteins synaptophysin and synaptotagmin tagged with green fluorescent protein (synaptophysin-EGFP and synaptotagmin-EGFP). We found that microglia prestimulated by inflammatory cytokines to produce nitric oxide (NO) and tumor necrosis factor- $\alpha(\mathrm{TNF}-\alpha)$ focally suppressed the axonal motility of labeled vesicle precursors at the point of contact between activated glia and axons, as measured using confocal microscopy of fluorescence recovery after photobleaching (FRAP).

We found that direct application of either TNF- $\alpha$ or a short-term NO donor to cultured hippocampal neurons inhibited axonal motility of both synaptophysin-EGFP and synaptotagmin-EGFP. Furthermore, TNF- $\alpha$ inhibited axonal transport of mitochondria in a similar manner.

Consistently, TNF- $\alpha$ induced axonal transport impairment normalized again after 6-8 hours of TNF- $\alpha$ application.

Inhibition of axonal transport by NO or TNF- $\alpha$ was associated with a significantly increased fraction of immobile particles. Furthermore, inhibition of axonal transport was dependent on phosphorylation of c-jun NH2-terminal kinase (JNK).

In particular, we show that both NO and TNF- $\alpha$ stimulated phosphorylation of JNK in axons. In experiments with both genetically labeled mitochondria and synaptic vesicle precursors, we observed that the velocity of the remaining mobile particles was largely unchanged. This suggested a model where TNF- $\alpha$ produced by activated glial cells in 
inflammatory or degenerative brain diseases acts on axons by inhibition of cargo transport and dissociation kinesin motor protein from microtubules.

Confocal microscopy and lifetime-based Förster resonance energy transfer (FRET) analysis were performed on primary cultured neurons to analyse the effect of TNF- $\alpha$ on the axonal mitochondrial transport system. TNF- $\alpha$ induced detachment of the heavy chain kinesin family-5B (KIF5B) protein from tubulin in axons, but not cell bodies as determined by lifetime based FRET analysis. Dissociation of KIF5B from tubulin after TNF- $\alpha$ treatment was also dependent on phosphorylation of JNK.

Thus, overt production of inflammatory mediators by activated microglial cells blocks the motility of synaptic vesicle precursors and mitochondria via phosphorlyation of JNK and may cause axonal and synaptic dysfunction in inflammatory and degenerative brain diseases. 


\section{INTRODUCTION}

\subsection{Molecular mechanisms of brain injury}

The molecular mechanism of axonal injury in inflammatory brain diseases such as multiple sclerosis [1] and synapse loss in neurodegenerative diseases such as Alzheimer's disease [2] is not known. Several studies observed a close association between the number of activated microglial cells and axonal injury in multiple sclerosis [3, 4], microbial infection [5] and brain injury [6,7]. Furthermore, accumulation of $\beta$-amyloid precursor protein (APP), a sign of axonal transport disturbance, is observed in several inflammatory brain diseases including multiple sclerosis [8], microbial infections [5, 9], mechanical injury [10] and ischemia [11].

Intact axonal transport via kinesin motor protein is fundamental for normal function of synaptic connections and targeted deletion of kinesin motor proteins results in axonal degeneration [12].

Recently, it was suggested that axonal transport impairment is involved in early development of neurodegenerative diseases [13]. However, this question has not been addressed in detail.

Whilst pathologies associated with the later stages of interaction between axons and activated microglia such as axonal trans-section, are well characterized [14], little is known about the initial response of healthy axons to activated microglia. Such information would be valuable for the development of novel therapeutical approaches, which could aim to limit the damage caused to healthy nervous tissue caused by activated microglia [15].

\subsection{Microglial activation in the central nervous system}

The important role of microglia in various pathological conditions was first recognized by del Rio-Hortega, who first identified this class of cells [16]. Most of brain pathologies involve the microglia [17]. Microglial cells are the resident macrophages of the CNS, which form the brain's first line of defense and are in control of the immune response in the brain. Microglia form an essential link between the CNS, isolated from the rest of the immune system by the blood-brain barrier, and the general immune system. 
Their nature and identity have long been debated but it is now generally accepted that they are similar to cells of the mononuclear phagocyte lineage, and thus are unlike all other cell types in the CNS $[18,19]$. However, some few laboratories suggest that, based on in vitro experiments, microglia may be true glia of neuroectodermal lineage [20].

Microglia are capable of responding to very subtle alterations in their microenvironment, such as imbalances in ion homeostasis, before any signs of disease can be histologically detected [21]. One characteristic feature of microglia is their activation in the CNS at a very early stage in response to injury [22-25]. Microglia are generally inactive, or resting, but as was observed over a century ago, they rapidy change their morphology upon activation [26]. Microglial activation takes place in a rather stereotypic pattern, irrespective of the cause of the lesion. Activation of microglia displays a repertoire in terms of proliferation, migration to the site of injury, characteristic morphological, immunophenotypical and functional changes.

The development of resting microglia cells into full blown phagocytes occurs in response to cell death, and especially that of neuronal death. The shape of activated microglia can be highly variant, and depends on the particular pathology the microglia are responding to. The scavenger function of microglia becomes evident particularly under ischaemic or traumatic conditions $[16,26]$. Resident microglia play a part in tissue repair after injury, an similar to that of resident macrophages in peripheral organs. Both microglia and astrocytes are needed for tissue reconstitution after lesions, involving control of the blood-brain barrier and of the invasion of haematogenous cells, removal of proinflammatory cytokines and their downregulation by TGF- $\beta 1$.

In their role as phagocytes, they destroy invading micro-organisms, remove potentially deleterious debris, promote ensuing tissue repair by secreting wound-healing factors and thus facilitate the return to tissue homeostasis. Cytotoxic effects contribute to the function of microglia as tissue guardians in the brain [27].

Activated microglia are capable of releasing several potentially cytotoxic substances in vitro, such as free oxygen intermediates, NO, proteases, arachidonic-acid derivates, excitatory amino acids, quinolinic acid and cytokines [27-29].

Microglial activation is controlled by a positive feedback mechanism- resting microglia can be activated by inflammatory cytokines, which are in turn produced by the microglia 
themselves- leading to damage of healthy tissue surrounding the site of microglial activation. TNF- $\alpha$ produced by microglia can cause bystander damage during demyelination. Free oxygen radicals released by microglia have a neurotoxic effect in cocultures of neurons and microglia $[30,31]$.

\subsection{Motor proteins and axonal transport}

Many studies have been performed to understand the nature and characteristics of organelle tansport, particularly in highly polarized cells such as neurons [32-34]. A better understanding of the molecular nature of transport complexes can give many insights to how a cell services and regulates its many biological requirements.

A wide spectrum of motor proteins has been identified, which can be divided into two general classes: proteins responsible for anterograde transport (kinesins) and those utilized for retrograde transport (dyneins). These motors all share some common features, such as motor domains and a c-terminal which forms the interface between the motor protein and that motor protein's specific cargo.

It is widely supposed that different motor proteins, which all have different enzymatic characteristics (thus translating as different movement behaviour on the microtubule network) are responsible for different cargoes. Thus one can indirectly observe the behaviour of groups of motor proteins by monitoring the transport of their cargoes.

Synaptic vesicle precursors containing synaptophysin are largely synthesized and preassembled in the cell body and then transported over long distances to the axonal terminals usually via the kinesin motor protein KIF1A [35].

Synaptophysins are N-glycosylated membrane proteins, reported to interact with synaptotagmin I on synaptic vesicle membranes [36]. Immunoprecipitations of synaptic vesicles from rat brain with antibodies to synaptophysin demonstrate that synaptoporin is colocalized with synaptophysin on the same vesicles, although they do not interact with each other [37]. The presence of these two highly related proteins on the same vesicle suggests that they have similar but nonidentical functions. A mouse knockout of synaptophysin alone produces no detectable phenotype (although a defect in synaptic transmission was observed in a synaptophysin/synaptogyrin double mutant, suggesting functional redundancy for these proteins) [38]. All these proteins can potentially be used 
as marker of vesicle transport, and in the following study we chose to utilize both synaptophysin and synaptotagmin I.

\subsection{Mitochondria in the axon}

The mitochondrion derives its name from the Greek mitos (thread) + khondrion (granule), recognising their characteristic shapes. While generally very similar in diameter, mitochondria can have very different overall structures. In neurons, they range from 1 to $20 \mu \mathrm{m}$ in length [39]. Observations of fluorescently labelled mitochondria in living cells have shown them to be dynamic organelles capable of dramatic changes in shape. Mitochondria can fuse with one another, or split in two, a process which involves Dyamins [40]. Mitochondria have two functional membranes: the outer mitochondrial membrane completely encloses the organelle, serving as its outer boundary. The inner mitochondrial membrane is thrown into folds, or cristae, that project inward. The cristae surface houses the machinery needed for aerobic respiration and ATP formation, and their folded form increases that capacity by increasing the surface area of the inner mitochondrial membrane. Although the primary function of mitochondria is to convert organic materials into cellular energy in the form of ATP, mitochondria play an important role in most important metabolic processes [41-43]. They generate the ATP necessary to maintain transmembrane ionic gradients and are thought to play a role in the regulation of cytoplasmic calcium. Because diffusion of both ATP and calcium ions is limited in cytoplasm [44], the distribution of mitochondria is thought to tightly reflect the distribution of energy need and calcium flux. Thus, the movement and redistribution of mitochondria is vital for maintaining cellular homeostasis.

Active transport in cells is largely driven by three classes of motors: kinesins, dyneins and myosins. All of them need ATP for complete their task. Thus, the positioning of ATP-producing mitochondria in the cell has the potential to strongly affect transport characteristics of that cell.

Mitochondria themselves depend on motor proteins for their movement. So far, it is known that multiple anterograde moving motor proteins (Kif5B, Kif1B) are involved, and that retrograde transport of mitochondria is most likely mediated by dynein [45] but the regulation of this process is still not well studied. In particular, very little is known 
about mechanisms which are involved in the very fast switching evidently required to change motion from anterograde to retrograde directions [45, 46]. Some studies propose 'super complexes' of multiple motor proteins with different movement characteristics [45] which may explain rapid changes in direction.

\subsection{Adaptor proteins for kinesins}

Transport of synaptic vesicle precursor components is a highly regulated process. Several studies indicate that c-Jun N-terminal kinase (JNK) interacting proteins (JIP) serve as scaffolding proteins and associate with the kinesin motor protein family and cargo receptors. Particularly, data in C. elegans showed that unc-16, encoding a homolog of the mouse scaffolding protein JIP3, physically interacts with JNK and JNK kinases [47]. Pioneering work by the group of Goldstein in Drosophila melanogaster described that a homologue of the mammalian scaffolding protein JIP3 linked conventional kinesin-I to an unknown class of vesicles [48]. Data in C. elegans showed that unc-16, encoding a homologue of JIP3, physically interacts with JNK and JNK kinases [49]. Mutations of unc-16 or JNK resulted in mislocalization of synaptic vesicle markers such as synaptobrevin [47] and synaptotagmin I [49]. Also JIP1 and JIP2 have been identified to associate with and be cargoes of kinesin-I [50].

Furthermore, the JNK signaling scaffold protein JIP-1b connects the motor protein kinesin light chain to the synaptic vesicle protein APP and enables protein phosphorylation by JNK [51]. APP is widely supposed to be a transmembrane cargo receptor of synaptic precursor vesicles [52].

The scaffolding JIPs are also involved in the organization and facilitation of JNK signaling implicated in multiple processes, allowing a cell to mount an appropriate response to extracellular stress [53]. The finding that multiple types of JNK scaffolding proteins interact with kinesin-I and that JNK scaffolding proteins are involved in JNK signaling raises the question whether JNK signaling regulates axonal transport.

\subsection{Technical approach to determine dynamics of axonal cargos}

A well-known imaging technique used to study the motility of fluorescence molecules in living sample is fluorescence recovery (or redistribution) after photobleaching (FRAP) 
[54].

A high intensity light is used to irreversibly photo bleach a population of fluorophores in a target region, recovery of that fluorophore in that region is indicative of the dynamics. Quantification of fluorescence intensity over time is used to determine which fractions of particles are stationary or mobile, and can be used to infer velocities of populations of particles $[54,55]$.

In this thesis, fluorescence recovery after photobleaching (FRAP) was applied to analyze the axonal motility of synaptophysin tagged with enhanced green fluorescence protein (synaptophysin-EGFP) in living cultured hippocampal neurons in response to inflammatory stimuli such as activated microglia and its inflammatory mediators nitric oxide (NO) and tumor necrosis factor- $\alpha(\mathrm{TNF}-\alpha)$.

\subsection{Technical approach to determine interaction between motors and tubulin track}

In this study, we used fluorescence resonance energy transfer (FRET) as a non-invasive imaging method to characterize the interaction of kinesin motor proteins with microtubules in primary neuronal cultures. FRET, also called Förster transfer, named for Theodor Förster who, in the 1940s, quantitatively described the phenomenon, originates from a nonradiative dipole-dipole interaction between a donor and an acceptor fluorophore. The strong dependence of the energy transfer rate $k_{\mathrm{T}}$ and hence the energy transfer efficiency $E_{\mathrm{T}}$ on the donor-acceptor distance $R$, is described by:

$$
\begin{aligned}
& k_{\mathrm{T}}=\frac{1}{\tau_{\mathrm{D}}}\left(\frac{R_{0}}{R}\right)^{6} \\
& E_{\mathrm{T}}=\frac{R_{0}^{6}}{R^{6}+R_{0}^{6}}
\end{aligned}
$$

When two fluorophores are extremely close, the distance between these sites can be measured using the above formalism [56]. In particular, $t_{\mathrm{D}}$, donor fluorescence lifetime in the absence of acceptor; $R_{0}$, Förster distance at which $E_{\mathrm{T}}$ is $50 \%$; $R_{0}$ is dependent on the 
spectral overlap of the fluorophore pair used and typically has a value of $20-90 \mathrm{~A}^{\circ}$, enables the calculation of fluorophore distances in the range $10-100 \mathrm{~A}^{\circ}$ from their energy transfer efficiency.

The fluorescence lifetime is a direct indicator of this energy transfer rate from the excited molecules to the acceptor molecules [57]. Since the lifetime does not depend on the concentration of the fluorophore, FLIM is allows a more consistent measurement of energy transfer between fluorophores in samples with varying fluorescence intensity.

With FLIM techniques, FRET results are obtained from a single lifetime image of the donor [58-60]. The fluorescence lifetimes of typical fluorophores used in cell imaging are typically of the order of a few ns.

In this study, fluorescence lifetime imaging was achieved by time-domain techniques use pulsed excitation and record the fluorescence decay function directly, by time correlated photon counting [61].

Time-correlated single photon counting (TCSPC) combines a near-ideal counting efficiency with extremely high time-resolution. For a full description of equipment and data analysis, see "Materials and Methods". 


\section{MATERIAL AND METHODS}

\subsection{Neuronal cultures and transfection with EGFP or synaptophysin-EGFP}

Neuronal cultures were prepared from hippocampi of C57BL/6 mice embryos (E17) as described previously [62]. Hippocampi were isolated, dispersed mechanically and seeded in biomembrane optical dishes (Helmut Saur, Germany) or 4-well chamber culture dishes (Nunc GmbH\&Co. KG, Germany). The dishes were pretreated with poly-L-ornithin (0.01 $\mathrm{mg} / \mathrm{ml}$, Sigma, Germany) and laminin (10 $\mu \mathrm{g} / \mathrm{ml}$, Sigma, Germany). The cells were cultured in neuronal culture medium (BME, GibcoBRL, Invitrogen GmbH, Germany) supplemented with 2\% B-27 supplement, (GibcoBRL, Invitrogen GmbH, Germany), 1\% glucose (45\% glucose, Sigma, Germany) and 1\% fetal calf serum (FCS, PAN Biotech $\mathrm{GmbH}$, Germany). Cells were cultured for 5-10 days to obtain morphologically mature neurons.

Transfection of neurons was performed with a plasmid expressing EGFP (enhanced green fluorescent protein) alone or synaptophysin (rat synaptophysin p38) tagged with EGFP at the c-terminus under control of the human synapsin I promoter as previously described [15]. The plasmid p(synapsin).EGFP was kindly provided by Dr. S. Kügler [63], Dept. of Neurology, University of Göttingen, and p(CMV).p38-EGFP was kindly provided by Dr. C. Kaether, EMBL, Heidelberg [64].

Both genes were subcloned to produce the $\mathrm{p}$ (synapsin).synaptophysin-EGFP plasmid. In detail, EGFP was removed from the $\mathrm{p}$ (synapsin).EGFP plasmid by NotI/NheI restriction digestion. Synaptophysin -EGFP was cut by NotI/NheI restriction digestion and subcloned in the $\mathrm{p}$ (synapsin)-vector backbone. The subcloning was verified by control restriction enzyme digestion. The plasmid was purified using the EndoFree Maxi Kit (Qiagen, Germany). Transfection was performed during seeding of the neuronal cells by the Effectene Transfection Kit (Qiagen, Germany). The cells were incubated for 30 minutes with $0.5 \mu \mathrm{g}$ plasmid DNA per 1 x106 cells, $6 \mu$ l enhancer, $12 \mu 1$ Effectene and 85 $\mu l$ buffer. After transfection, the cells were washed in phosphate buffered saline (PBS) and suspended in neuronal culture medium. The average transfection efficiency was approximately $0.5 \%$ and the majority of transfected neurons showed plasmid expression from day 3-5 until day 10-14. After transfection neurons were cultured for 5-10 days 
before being used in the experiments. Neurons were treated with the short term NO donor (300 $\mu \mathrm{M}$ DEA/NONOate, Alexis Corp.), cGMP (0.2 mM 8-Bromo-cGMP, Sigma) or the NO synthase inhibitor aminoguanidine ( $2 \mathrm{mM}$, Sigma) as indicated in the text and figures. Neurons were pre-treated for 30-40 minutes with the JNK inhibitor (100 nM JNK Inhibitor II, Alexis Corp.) as indicated in the text and figures.

\subsection{Microglial cultures}

Microglial cells were prepared from the hippocampal region of postnatal day 5 (P5) C57BL/6 mice as previously described [65]. Briefly, meninges were removed mechanically and the cells were cultured in basal medium (BME, GibcoBRL, Invitrogen GmbH, Germany, 10\% fetal calf serum (FCS, PAN Biotech GmbH, Germany), 1\% glucose and 1\% L-glutamine for 25-30 days to form a confluent cell monolayer. To collect microglial cells the cultures were shaken on a rotary shaker $(220 \mathrm{rpm})$ for 2 hours. The detached microglial cells were cultured in normal culture dishes for 1 hour and nonadherent cells were removed. Purity of the isolated microglia was confirmed by flow cytometry analysis. For this, cells were incubated for 1 hour on ice with antiCD11b/CD18 biotinylated antibody (1: 100, PharMingen, BD Biosciences, USA) or negative isotype control antibody (PharMingen) and thereafter with streptavidin-FITC (1:100, Dianova, Hamburg, Germany). Analysis was done with a FACScalibur flow cytometer (BD Biosciences, USA). Life gating was performed with propidium iodide (Sigma, Germany) and the percentage of $\mathrm{CD} 11 \mathrm{~b} / \mathrm{CD} 18$ cells was determined according the isotype control (data not shown).

Microglial cells were cytokine-stimulated by combined treatment with interferon-gamma (recombinant murine IFN-gamma, $100 \mathrm{U} / \mathrm{ml}$, HyCult Biotechnology, The Netherlands) and interleukin-1 $\beta$ (murine IL-1 $\beta, 10 \mathrm{ng} / \mathrm{ml}$, Roche Molecular Biochemicals) for 72 hours as indicated in the text. Microglial cells were pre-treated for 60 minutes with the NOS inhibitor aminoguanidine ( $2 \mathrm{mM}$; Sigma) as indicated in the text. Microglial cells were CellTracker-labeled according the manufacturers instructions (CellTracker orange CMTMR, Molecular Probes, Leiden, The Netherlands) and added in a fixed ratio of 1:2 (microglia : neurons) to the neuronal cultures. 


\subsection{Transfection of neurons with pMH4.mito-YFP}

The pMH4-HSYN-Mito -EYFP vector is designed to be used for the fluorescent labeling of mitochondria. Fluorescence can be observed in living or fixed neurons by microscopy. The plasmid encodes a fusion of EYFP and the mitochondrial targeting sequence from subunit VIII of human cytochrome c oxidase, under the human synapsin promotor. The EYFP gene (enhanced yellow fluorescent protein with the emission of the chromophore to yellow-green from green. The fluorescence excitation maximum of EYFP is $513 \mathrm{~nm}$, and the emission spectrum has a peak at $527 \mathrm{~nm}$. In addition to the four chromophore mutations, the coding sequence of the EYFP gene contains more than 190 silent base changes corresponding to human codon-usage preferences, which increase the translational efficiency of the EYFP transcript. Mitochondrial targeting sequence from subunit VIII of human cytochrome c oxidase linked in frame with eYFP, and sequenced. The plasmid was purified using EndoFree Maxi Kit (Qiagen, Germany). Transfection was performed during seeding of the cells by the Effectene Transfection Kit (Qiagen, Germany) with $0.5-1 \mu \mathrm{g}$ DNA per $1 \times 106$ cells, $4-8 \mu 1$ enhancer, $12 \mu 1$ Effectene and 85 $\mu 1$ buffer for a period of $30 \mathrm{~min}$. After transfection, the cells were washed in PBS and suspended in BME-basal neuronal medium. The cells were seeded in 4-well chambers (Nunc GmbH\&Co. KG, Germany) or in membrane-bottom optic dishes (Helmut Saur, Germany) with a density of 150000 cells $/ \mathrm{ml}$.

\subsection{In vivo imaging and FRAP analysis}

FRAP was performed using Leica TCS laser scanning confocal microscopy with 40x objective as described with some modifications [66]. The medium of the neuronal cultures was removed and substituted with image buffer containing $142 \mathrm{mM} \mathrm{NaCl}, 5.4$ $\mathrm{mM} \mathrm{KCl}, 1.8 \mathrm{mM} \mathrm{CaCl} 2,1 \mathrm{mM} \mathrm{NaH2PO} 4,25 \mathrm{mM}$ HEPES, $5 \mathrm{mM}$ glucose, $0.8 \mathrm{mM}$ $\mathrm{MgCl} 2 \mathrm{MgSO} 4$ in $\mathrm{ddH} 2 \mathrm{O}, \mathrm{pH}=7.4$. The cell culture dishes were placed on the heated stage in a heated chamber of a Leica LSC confocal microscope (Leica, Germany) and kept during the analysis at $35-37{ }^{\circ} \mathrm{C}$. Bleaching was performed with $100 \%$ laser power and zoom area $32 \mathrm{x}$ within 20 scanning frames of an $20 \mu \mathrm{m} \times 20 \mu \mathrm{m}$ area along a synaptopyhsin-EGFP or EGFP transduced axon. In all experiments bleaching was more than $80 \%$ assuming a Gaussian distribution of remaining GFP-labeled molecules. For 
postbleaching in vivo imaging, the laser power was turned to minimum and further reduced to $10-20 \%$ according the software control panel to avoid photobleaching and phototoxicity. Photobleaching with this reduced laser power was less than $1 \%$. Samples were imaged each 10 - 60 seconds over 15 minutes after photobleaching. Collected data were fitted to the following equation:

$\mathrm{F}(\mathrm{t})=\operatorname{span}\left(1-\mathrm{e}^{-\mathrm{kt}}\right)+$ bottom

The bottom was defined as the intensity of the first image after photobleaching, plots were generated from background subtracted images using Matlab scripts, following analysis [55]. Briefly the signal $\mathrm{F}(\mathrm{t})$ was measured, as mentioned, in an area of interest and analyzed, normalized and plotted. Each normalization was made to obtain a range of $\mathrm{F}(\mathrm{t})$ between [0-1] arbitrary units, where 1 is the initial fluorescence intensity, and 0 the intensity immediately after photobleaching.

The half-time value $t_{1 / 2}$ was calculated accordingly. The final fluorescence intensity $F(\infty)$ was less then the pre-bleaching fluorescence intensity since a proportion of the fluorescence molecules were not mobile. The mobile fraction (i.e. those particles moving) was defined as the span of the fluorescence recovery after photobleaching.

Immunohistochemestry for neurofilaments and tau after FRAP was performed to show that there is not phototoxicity or cytoskeleton damage after bleaching, Fig. 15.

\subsection{In vivo imaging by tracking mitochondria}

The neuronal cells were cultured in LabTek chambered coverglass slides. The original medium of the neuronal cultures was removed and substituted with image buffer containing $142 \mathrm{mM} \mathrm{NaCl}, 5.4 \mathrm{mM} \mathrm{KCl}, 1.8 \mathrm{mM} \mathrm{CaCl} 2,1 \mathrm{mM} \mathrm{NaH} 2 \mathrm{PO} 4,25 \mathrm{mM}$ HEPES, $5 \mathrm{mM}$ glucose, $0.8 \mathrm{mM} \mathrm{MgCl} 2$ in ddH2O, $\mathrm{pH}=7.4$. The cell culture dishes were placed on the heated stage of the confocal microscope Leica LSC (Leica, Germany) and kept during the analysis at $35-37{ }^{\circ} \mathrm{C}$.

Mitochondria were tracked through a series of picture (each frame every $20 \mathrm{sec}$ ) taken by confocal microscopy.

We used View5d (image plugin made by Dr. Rainer Heintzmann, 
www.gwdg.de/ rheintz/View5D/ ) combined with Matlab. The analysis was performed by manual tracking and by kymograph, a graphical representation of spatial position over time in which one spatial axis represents time. After analysis, we could define velocity, direction, mobile fraction of mitochondria and immobile fraction of mitochondria to compare in different situations.

\subsection{Detection of iNOS gene transcripts, TNF- $\alpha$ and NO release by microglia}

RNA was isolated from microglia either untreated or treated for 72 hours with IFNgamma $(100 \mathrm{U} / \mathrm{ml})$ and IL-1 $\beta(100 \mathrm{U} / \mathrm{ml})$ by the RNEasy Kit (Qiagen). Reverse transcription of RNA was performed with Moloney murine leukemia virus transcriptase (Invitrogen) and hexamer random primers (Roche Molecular Biochemicals). Forward and reverse primers for iNOS, TNF $\alpha$ and GAPDH were chosen from two different exons and were, respectively, iNOS (5'-AAGCTGCATGTGACATCGAC-3' ; 5'TGCTGAAACATTTCCTGTGC-3') , TNF ( 5-GGGGTGATCGGTCCCCAAAGG-3 ; 5-CGGGGCAGCCTTGTCCCTTG-3 ); and glyceraldehyde-3-phosphate dehydrogenase (GAPDH) (5'-TCCGCCCCTTCTGCCGATG-3'; 5'-CACGGAAGGCCATGCCAGTGA$\left.3^{\prime}\right)$. The PCR reaction was performed with the transcribed cDNA probes by 30 cycles with deoxyribonucleotide triphosphates (Amersham Bioscience), denaturated primers (MWG, Germany), Ampli Taq polymerase (Perkin-Elmer, Roche Molecular Systems) on a programmed thermocycler (MultiCycler, MJ Research Inc.). PCR amplification with primers for GAPDH served as control for the quality and quantity of the transcribed cDNA. PCR reactions were analyzed on an agarose gel containing ethidium bromide, Fig. $1 b$.

To measure the release of NO from microglial cells, the Griess Reagent System (Promega) was used according the manufacturers guidelines. The amount of nitrite $\left(\mathrm{NO}_{2}\right)$ was measured as a stable and nonvolatible breakdown product of NO. The system was calibrated with a standard curve. The detection limit was $2.5 \mu \mathrm{M}$ nitrite. Microglial cells were treated for 72 hours with IFN-gamma $(100 \mathrm{U} / \mathrm{ml})$ and IL-1 $\beta(100 \mathrm{U} / \mathrm{ml})$, Fig $1 \mathrm{a}$.

\subsection{Immunohistochemistry}

Hippocampal neurons transfected with synaptophysin-EGFP or synaptotagmin-EGFP 
were cultured for 1 week, fixed with $4 \%$ paraformaldehyde, permeabilized with $0.1 \%$ Triton X-100, and incubated with a mouse monoclonal antibody specific for tau microtubule-associated protein (tau-1, 1:200, clone PC1C6; Chemicon), followed by secondary fluorochrome Cy3-conjugated goat antibody directed against mouse $\operatorname{IgG}$ (1:200; Dianova). Alternatively, fixed neurons were labeled with mouse monoclonal antibody specific for synaptobrevin/VAMP2 directly conjugated with Oyster 556 (1:200, IgG1; Synaptic Systems)..A mouse monoclonal antibody specific for phosphorylated JNK (1:200, Santa Cruz Biotechnology, Santa Cruz, CA), followed by secondary fluorochrome Cy3-conjugated goat antibody directed against mouse $\operatorname{IgG}$ (1:400,Dianova). Subsequently, after washing, cells were incubated with an axon-specific mouse monoclonal antibody directed against tau (tau-1, 1:200, PC1C6; Chemicon) and secondary FITC goat antibody directed against mouse $\operatorname{IgG}(1: 400$; Dianova).

Rat monoclonal antibodies directed against TNFRI ( $2 \mu \mathrm{g} / \mathrm{ml1}: 50$; HM-104; Biermann, Bad Nauheim, Germany) and TNFRII (1:502 $\mu \mathrm{g} / \mathrm{ml}$; HM-102; Biermann) followed by secondary fluorochrome Cy3FITC-conjugated goat antibody directed against rat IgG (10 $\mu \mathrm{g} / \mathrm{ml1}: 200$; Dianova).

A neuron-specific mouse monoclonal antibody specific for $\beta$-tubulin IIIMAP2 $(1 \mu \mathrm{g} / \mathrm{ml}$ 1:400; Sigma) and secondary FITC Cy3 goat antibody directed against mouse IgG (10 $\mu \mathrm{g} / \mathrm{ml} 1: 200$; Dianova). Baseline labeling was determined with rat control antibodies and secondary fluorochrome $\mathrm{Cy} 3$-conjugated goat antibodies directed against rat IgG.

Mouse monoclonal antibody specific for phosphorylated JNK (2 $\mu \mathrm{g} / \mathrm{ml}$, Santa Cruz), followed by secondary fluorochrome Cy3-conjugated goat antibody directed against mouse IgG ( $2 \mu \mathrm{g} / \mathrm{ml}$, Dianova, Hamburg).

A dendrite-specific mouse monoclonal antibody directed against microtubule associated protein-2 (MAP2, $2 \mu \mathrm{g} / \mathrm{ml}$, Sigma) and secondary FITC-conjugated goat antibody directed against mouse $\operatorname{IgG}(2 \mu \mathrm{g} / \mathrm{ml}$, Dianova, Hamburg). Baseline labeling was determined with mouse control antibodies and secondary fluorochrome $\mathrm{Cy}-3$ conjugated goat antibodies directed against mouse IgG.

Mouse monoclonal antibody specific for phosphorylated JNK ( $2 \mu \mathrm{g} / \mathrm{ml}$, Santa Cruz), followed by secondary fluorochrome Cy3-conjugated goat antibody directed against mouse IgG $(2 \mu \mathrm{g} / \mathrm{ml}$, Dianova, Hamburg). 
A dendrite-specific mouse monoclonal antibody directed against microtubule associated protein (TAU, $2 \mu \mathrm{g} / \mathrm{ml}$, Sigma) and secondary FITC-conjugated goat antibody directed against mouse IgG ( $2 \mu \mathrm{g} / \mathrm{ml}$, Dianova, Hamburg). Baseline labeling was determined with mouse control antibodies and secondary fluorochrome $\mathrm{Cy}-3$ conjugated goat antibodies directed against mouse IgG. Optical sections along the $z$-axis were scanned with a confocal laser-scanning microscope (Leica, Nussloch, Germany) equipped with a 63x or 40x oil objective

\subsection{Lifetime based FRET analysis}

Hippocampal neurons were cultured for 5-10 days, fixed with 4\% paraformaldehyde and then incubated with a mouse monoclonal antibody specific for KIF5B (1:200, Abcam), followed by secondary fluorochrome FITC-conjugated goat antibody directed against mouse IgG (1:400, Fab-fragments directed against Fab, Dianova). After washing, cells were incubated with a mouse monoclonal antibody directed against $\beta$-tubulin III ( 1:400; Sigma) and secondary Cy3-conjugated goat antibody directed against mouse IgG (1:400; Fab-fragments directed against Fab, Dianova). As a negative control for the FRET analysis neurons were immunolabeled with mouse monoclonal antibody directed against KIF5B (1:200, Abcam), followed by secondary FITC-conjugated antibody directed against mouse IgG (1:400, Fab-fragments directed against Fab, Dianova). Then neurons were co-labeled with Cy3-conjugated mouse monoclonal antibody directed against neurofilament (1:400, Sigma). Classic confocal laser-scanning microscope (Leica) was performed with a 40x oil objective. Neurons were treated with $20 \mathrm{ng} / \mathrm{ml}$ TNF for 20 minutes or pre-incubated for 5 minutes and co-treated with JNK inhibitor (SP600125; $100 \mathrm{nM}$ final) or TNF receptor I-IgG fusion protein $(20 \mu \mathrm{g} / \mathrm{ml}$; gift from Dr. Werner Lesslauer, Roche [62]) as indicated in the text and figures.

Direct protein-protein interactions can be visualized via Föster Resonance Energy Transfer (FRET). FRET is a non-radiative, dipole coupling process, whereby energy from an exited donor (fluorophore) is transferred to an acceptor (fluorophore), which is in very close proximity. The efficiency of this process may be used to estimate the proximity of the two fluorophores [67]. Fluorescence Lifetime Imaging Microscopy (FLIM) is a technique suitable for studying protein interactions in space and time in fixed and living 
samples through the detection of FRET [68]. Two-photon excitation allows the detection of photons from one focal plane, thus improving the signal-to-noise ratio of the acquired lifetime maps. We decided to use one of the most common FRET pairs (FITC//Cy3), well known for quantum efficiency and stability. All FLIM measurements were done with a 63x oil or 40x oil objective lens on a specific multi-photon microscopy system consisting of a time-domain FLIM setup (Becker-Hickl), an upgraded TSC-SP2 AOBS laser scanning confocal microscope (Leica Microsystems) and a Ti:Sapphire Mira900 twophoton laser pumped by a Verdi-V8 laser (Coherent) in the mode-locked femtosecondpulsed regime. The laser was tuned to $900 \mathrm{~nm}$ for proper two photon excitation of FITC [69]. An emission filter wheel was placed between the output port of the scanning-head and the time domain-FLIM detector, an MCP-PMT (R3809U-50 by Hamamatsu Photonics). A $520 \pm 15 \mathrm{~nm}$ filter was used for FITC detection. The time-resolved fluorescence decays were reconstructed by time correlated single photon counting (TCSPC). The acquisition board (SPC830) and software (SPCImage) were from Becker

$\&$ Hickl. The gate/rate that we obtained was between $10^{3}$ to $10^{4}$ photons/second with peak rates of $10^{5}$ photons/second. Acquisition time was fixed to 900 seconds at an excitation power of $0.5-0.6 \mathrm{~W}$. Using this system, 200 counts are required for a reliable mono-exponential decay fit and 1000 counts can give approximately $5 \%$ of statistical error in the lifetime estimations [70]. Lifetime images obtained were coded in pseudocolors with lifetime ranges of 1.0 to 1.9 nanoseconds in red (shorter lifetimes indicating FRET) and lifetime ranges of 1.9 to 4.0 nanoseconds in green (long lifetimes indicating NO FRET). Furthermore, lifetime values are presented as histograms. To quantify the percentage of axons showing a lifetime signal reflecting FRET, random images were analyzed. Neurons were treated with TNF (20 ng/ml for 20 minutes), TNF plus JNK inhibitor (SP600125; $100 \mathrm{nM}$ ) as indicated in the text and figures.

\subsection{The limits of the FRET system}

Whilst FRET measurements as a technique to define protein-protein interactions have been extant for many years, it is only recently that FRET measurements are being used as part of a standard repertoire of techniques for biology. Therefore, it is only now that 
practical problems are being encountered. Thus, I think it is reasonable to describe my personal experience in using this system:

It is impossible to have the perfect dyes for donor and acceptor: in theory they have to be photostable, have a high excitation coefficient, high quantum yield of emission, show small intensity fluctuations, introduce zero perturbance on the host and finally be commercial available. In addition it must be ideal for a FRET pair, large spectral separation, and comparable emission quantum yield for both donor and acceptor. We found that the FITC-Cy3 pair was sufficient for our purposes. In particular, we found that it was most important to have bright samples for imaging- we consistently saw that extending the imaging time for dim samples still produced much lower quality lifetime images than shorter exposures of bright samples, even if the numbers of collected photons were the same.

It is necessary to have a perfectly clean coverslip. These impurities give rise to fluorescence backgrounds, which contaminate lifetime measurements. In neuronal culture we can not use detergent, as even trace amounts can compromise the culture. We recommend extended washing of the coverslips.

A most significant problem for biological assays is that labeling proteins with dyes in vivo significantly affect molecular reaction kinetics. In general, large fluorophores like GFPs can locally compromise the stability of the molecular reactions, or the functionality of proteins. Use of antibodies can avoid this problem, with the limit that this usually precludes in vivo FRET and of course strongly amplifies the problem of finding complimentary antibodies with proper orientation and distance.

Photobleaching remains a problem for all XFP dyes. I found this to be especially true in my setup where use of the two photon and long time acquisition can badly compromise the experiment. Using antibodies, this situation changes and usually in normal conditions more than $10^{5}$ photons can be detected, and this data can be acquired in relatively controlled way.

Furthermore, use of GFP and mRFP can produce artifactual FRET: during the setup of the system, I constructed typical FRET pairs (Cerulean-YFP and EGFP-mRFP) in tandem by a short linker. In those cases, I obtained positive control values of 20-40\% FRET. I was surprised to find that in negative controls, in cells doubly transfected with 
cytoplasmic CMV-GFP and CMV-mRFP- the XFP proteins still physically interact. Using two techniques (acceptor photobleaching and by time-domain FLIM) I could show an artifactual value of FRET of about 5-10\%. This phenomenon, if persistent can strongly compromise sensitive FRET experiments such as looking for single-pixel FRET, or screening when one looks for small values of FRET. I think in my case this error is avoided by using antibodies.

Whilst the use of labeled secondary antibodies was the best solution for us, this system has not only positive aspects. It is very important to control for the risk of cross reaction between antibodies. In my case, where the staining was made by using 2 primary and 2 secondary antibodies, it is clear how many degrees of freedom my system has. It took a very long time to establish the correct combination, which is very expensive not only in terms of time but in money as well.

Another problem is that one always has to use the same set of antibodies, as even for monoclonal antibodies a change in lot number can drastically change the population of fretting molecules. In practical terms, for the 4 different antibodies one needs for such an experiment, one has to keep enough antibodies for perform all necessary experiments and controls. And finally, for me the most problematic difficulty is that this means that the repeatability of one's experiment is strongly correlated with the availability of suitable antibodies.

\subsection{Immunprecipitation}

Protein was extracted from cultured hippocampal neurons by lysis buffer of cells either untreated or treated for 20 minutes by TNF (20 ng/ml). For immunoprecipitation cell lysates were incubated with either antibodies directed against $\beta$-tubulin III $(2 \mu \mathrm{g} /$ reaction; Sigma) or antibodies directed against KIF5B ( $2 \mu \mathrm{g} /$ reaction; Abcam) at $4^{\mathrm{o}}$ for one hour. Subsequently, $20 \mu \mathrm{l}$ of protein G sepharose beads (Amersham Biosciences, Freiburg, Germany) were added. The precipitated proteins as well as total protein lysates were analyzed by Western blotting with anti- $\beta$-tubulin III (Sigma). In a second step the membrane was re-blotted with anti-JNK antibodies (2 $\mu \mathrm{g} /$ reaction; Santa Cruz). Furthermore, protein lysates were precipitated by antibodies directed against $\beta$-tubulin III ( $2 \mu \mathrm{g} /$ reaction; Sigma) and protein G sepharose followed by Western blot analysis 
with anti KIF5B and re-blotted anti-JNK antibodies ( $2 \mu \mathrm{g} /$ reaction; Santa Cruz). Western blotting was performed with the NuPAGE electrophoresis system (Invitrogen) and the ECL Advance Western Blotting Detection Kit (Amersham Biosciences).

\subsection{Statistical analysis}

For statistical analysis t-test and Mann-Whitney U test were applied by SPSS software as indicated in the text and figures. Data of FRAP were analyzed by MatLab/Mathwork software and Excel Software (Microsoft). Statistical analysis of FRAP was performed using two-tailed t-test between the groups. 


\section{RESULTS}

\subsection{Analysis of vesicle dynamics by FRAP}

Cultured hippocampal neurons derived from embryonic mice were transfected with synaptophysin-EGFP under control of the synapsin I promoter to achieve nearphysiological levels of expression. The neurons were used for experiments at day 5-10, when the EGFP signal was mainly localized in the axon as showed in immunohistochemistry samples, Fig. 2.

Confocal laser scanning microscopy of synaptophysin-EGFP in living neurons demonstrated that individual small vesicle-like structures were moving along the axon. However, the movements could not sufficiently be followed over long distances and separated from the immobile synaptophysin-EGFP structures.

In order to measure the axonal motility of synaptophysin-EGFP, we adopted the fluorescence recovery after photobleaching (FRAP) technique, which is widely used to determine the diffusion of fluorescent molecules in living cells. A $20 \mu \mathrm{m}$ long segment of the axon was bleached with high laser intensity and recovery of the fluorescence signal over time was measured with low laser power each 10-60 seconds (Fig. 2). The motility of axonally transported synaptophysin-EGFP is dependent on the mobile fraction of transported synaptophysin and the half-time value $t \frac{1}{2}$ of the fluorescence recovery curve, which is inversely proportional to the velocity of the transported synaptophysin-EGFP. The half-time value $t^{1} / 2$ of the fluorescence recovery after photobleaching (FRAP) was determined from the equation of the measured fluorescence intensity over time. The relation of mobile synaptophysin-EGFP compared to immobile synaptophysin was determined from the pre-bleaching fluorescence intensity and the calculated maximum of fluorescence recovery, Fig. 2d.

First, neurons were transfected with EGFP alone, which has been shown to freely diffuse within the cytoplasm. Then, a $20 \mu \mathrm{m}$ long segment of the axon was bleached. Within 1-2 seconds, the bleached axonal segment was completely filled up by EGFP confirming rapid and free diffusion of EGFP. Next, neurons were transfected with synaptophysinEGFP, which has been shown to be integrated as a membrane molecule in synaptic vesicle precursors [64]. Fluorescence recovery of the synaptophysin-EGFP signal after 
bleaching was relatively slow and lasted more than 600 seconds, Fig. 2d. The synaptophysin-EGFP filled up the bleached axon preferentially from the proximal side, indicating that synaptophysin-EGFP was mainly transported anterogradely.

\subsection{Microglia culture and activation}

Neuropathological data suggested a correlation between axonal transport disturbance and activated microglial cells. Therefore, we asked whether microglial cells stimulated to release inflammatory mediators might affect the axonal transport of synaptophysin. Microglial cells were isolated from mixed glial culture derived from postnatal mouse brain tissue. Flow cytometry analysis revealed that $96.1 \%$ (+/-7 \% SD) of isolated cells expressed the microglial marker CD11b/CD18 on the cell (data not shown). Microglial was stimulated by combined treatment with the proinflammatory cytokines interferongamma and interleukin- $1 \beta$ for 72 hours, and showed the characteristic morphologies of activated microglia (data not shown ).

The cytokine-stimulated microglial cells were labeled with a vital cell membrane red fluorescence dye and added to cultured hippocampal neurons transfected with synaptophysin-EGFP. The microglial cells appeared to bind to axons within a few minutes, Fig. 3.

\subsection{Mimicking the effect of nitric oxide (NO) and study vesicle transport}

To mimic the effect of reactive nitric oxide (NO) released by microglia, we added a short term NO donor (DEA/NONOate) to the cultured neurons and measured the recovery of the fluorescence signal after photobleaching of synaptophysin-EGFP. DEA/NONOate is known to release reactive NO within a few minutes (half-life of 2.1 minutes) under the performed analysis conditions (at $37^{\circ} \mathrm{C}$ in aqueous solution at physiological $\mathrm{pH}$ ) [71].

The half-time value $t^{1} / 2$ of the FRAP, which is inversely proportional to the velocity of synaptophysin-EGFP, was unchanged at 5-10 minutes after NO donor treatment and only slightly increased after 30 minutes of NO donor treatment, Fig. 4. After 120 minutes treatment with $300 \mu \mathrm{M}$ DEA/NONOate, the value returned back to levels comparable to untreated neurons. This demonstrates that the speed of mobile vesicles is largely unaffected by treatment with NO. Detailed analysis demonstrated that there was a 
significant decrease in the portion of mobile particles (mobile fraction) of synaptophysinEGFP after treatment with $\mathrm{NO}$, indicating that $\mathrm{NO}$ reduced the percentage of synaptophysin-EGFP transported along the axon. The mobile fraction of synaptophysinEGFP decreased from $0.65+/-0.18$ SD to $0.29+/-0.07$ SD after 5 minutes treatment with $300 \mu \mathrm{M}$ DEA/NONOate, Fig 4c.

Two major routes of NO signaling in neurons are known, the cGMP signaling pathway and S-nitrosylation of proteins [72]. To analyze whether stimulation of cGMP might modulate motility of synaptophysin-EGFP, we treated neurons with 8-Bromo-cGMP, a membrane-permeant analogue of cGMP. Treatment with $0.2 \mathrm{mM} 8$-Bromo-cGMP for 5 10 minutes or 30-35 minutes did not modulate axonal motility of synaptophysin-EGFP, Fig. 4. Furthermore, blocking endogenous neuronal NOS with high concentrations of the inhibitor aminoguanidine $(2 \mathrm{mM})$ did not affect axonal motility of synaptophysin-EGFP, Fig. 4.

\subsection{Phosphorylation JNK after treatment with NO}

Nitric oxide has been shown to positively stimulate c-Jun N-terminal kinase/stressactivated protein kinase (JNK) in endothelial cells [73], cardiomyocytes [74] and negatively regulate $\mathrm{JNK}$ in interferon-gamma stimulated macrophages by means of Snitrosylation [75]. Furthermore, it has been suggested that JNK is a possible modulator of kinesin-mediated axonal transport $[13,76]$.

First, phosphorylation of JNK in axons was studied after treatment with NO donor. Immunolabeling of the phosphorylated form of JNK was performed with a specific monoclonal antibody in neurons transfected with synaptophysin-EGFP. While untreated neurons showed no or very low fluorescence signal for phosphorylated JNK in neurites, neurons treated for 10 minutes with $300 \mu \mathrm{M}$ DEA/NONOate and identified by doublelabeling with antibodies directed against the axon protein microtubule associated protein (Tau) showed intense labeling of axons, Fig. 6.

Phosphorylation of the all three JNK family members (JNK-1, JNK-2 and JNK-3) was blocked with the inhibitor SP600125 JNK Inhibitor II (concentration $100 \mathrm{nM}$ ) in the neuronal cultures. 


\subsection{Effect of JNK-inhibitor on movement of synaptophysin-EGFP}

Interestingly, pre-treatment of neurons with the $\mathrm{JNK}$ inhibitor neutralized the effect of NO donor and TNF- $\alpha$ on axonal motility of synaptophysin-EGFP.

The neurons were pre-incubated for at least $30 \mathrm{~min}$ with $100 \mathrm{nM}$ JNK inhibitor II. The inhibitor alone did not influence the motility and transport of synaptophysin-EGFP as determined by FRAP, Fig. 5, and by the cross-correlation analysis (From Petra Dietrich, data not shown). Then, the NO donor was added to neurons pre-treated with the JNK inhibitor and cross-correlation data were recorded at the same position in the axon. The JNK inhibitor prevented the effect of NO on axonal motility of synaptophysin-EGFP, Fig. 5. The same results were obtained when repeating these experiments by tracking synaptotagmin-EGFP, Fig. 7.

\subsection{Expression of TNF receptors on axons of cultured hippocampal neurons}

Hippocampal neurons cultured for 5-8 days were analyzed for expression of tumor TNF receptors by immunofluorescence labeling. Neurons were labeled with antibodies directed against TNF receptor I or TNF receptor II. Double-labeling was performed by monoclonal mouse antibodies directed against the axonal marker protein tau. Analysis by confocal microscopy demonstrated that the majority of axons identified by staining with tau showed immunostaining for TNF receptor I and II, Fig. 8. In total, 50\% +/- $10 \%$ (mean +/- SD) of axons were labeled with antibodies against TNF receptor I and $40 \%+/-$ $20 \%$ of axons were labeled with antibodies directed against TNF receptor II, Fig. 8.

\subsection{Phosphorylated JNK in axons after treatment with TNF}

Phosphorylation of JNK is the result of the inflammatory cytokine TNF signaling in most cell types. Therefore, we analyzed phosphorylation of JNK in axons after treatment of neurons with TNF- $\alpha$. Cultured hippocampal neurons were treated with TNF- $\alpha(20 \mathrm{ng} / \mathrm{ml})$ for 20 minutes and activity of JNK was analyzed by immunohistochemistry with specific antibodies directed against phosphorylated JNK. Axons were identified by double labeling with antibodies directed against tau. In untreated neurons phosphorylated JNK was detected in neuronal cell bodies, but not in axons, Fig. 9a. After treatment of neurons with TNF- $\alpha$, strong immunolabeling of axons with specific antibodies directed against 
phosphorylated JNK was detected by confocal microscopy, Fig. 9b. Quantification of tau positive axons showed that almost all treated axons $(84 \%+/-13 \%$; mean $+/-\mathrm{SD})$ expressed phosphorylated JNK, while in untreated neurons a minority of axons $(11 \%+/$ 7\%) showed immunolabeling for phosphorylated JNK, Fig. 9c.

\subsection{Association between KIF5B, $\beta$-tubulin-III and JNK}

Recently, molecular interaction was observed between JNK, JNK-interacting protein 3 (JIP3) and kinesin-1 [77]. Therefore, we performed co-immunoprecipitation to analyze whether JNK forms a complex together with the motor protein kinesin heavy chain isoform KIF5B. Protein lysates were obtained from cultured hippocampal neurons and immunoprecipitated with antibodies directed against $\beta$-tubulin-III or KIF5B. Immunodetection after Western blotting demonstrated that JNK precipitated together with $\beta$-tubulin-III and KIF5B, Fig. 9d. Thus, immunoprecipitation indicated that JNK forms a complex together with KIF5B and $\beta$-tubulin-III. No difference in the amount of JNK or KIF5B bound to $\beta$-tubulin-III in immunoprecipitated lysates derived from whole cell cultures was detected after treatment of neurons with TNF $(20 \mathrm{ng} / \mathrm{ml})$ for 20 minutes, Fig. 9e.

\subsection{Dissociation of KIF5b from $\beta$-tubulin-III after TNF treatment in axons}

Since JNK, KIF5B and $\beta$-tubulin-III formed a complex and TNF- $\alpha$ treatment induced phosphorylation of JNK in axons, we analyzed the effect of TNF- $\alpha$ on the molecular interaction between KIF5B and $\beta$-tubulin-III at a subcellular level. Lifetime-based Förster resonance energy transfer (FRET) analysis was performed to allow subcellular localization of the molecular interaction between KIF5B and $\beta$-tubulin-III. Cultured hippocampal neurons were double-immunolabeled with monoclonal antibodies directed against KIF5B marked with the fluorophore FITC (KIF5B-FITC) and monoclonal antibodies directed against $\beta$-tubulin-III marked with the fluorophore Cy3 ( $\beta$-tubulin-IIICy3). As a negative control, neurons were double-immunolabeled with monoclonal antibodies KIF5B-FITC and monoclonal antibodies directed against neuroflilament marked with fluorophore Cy3 (neurofilament-Cy3). Furthermore, neurons were solely 
labeled with antibodies KIF5B-FITC to determine the regular lifetime as a control. First, confocal fluorescence intensity based images were obtained showing co-localization of KIF5B and $\beta$-tubulin-III in axons irrespective of TNF- $\alpha$ and JNK inhibitor treatment, Fig. 10.

Second, fluorescence lifetime images were obtained from KIF5B-FITC by two-photon excitation and time correlated single photon counting. An emission filter for KIF5B-FITC detection was placed between the output port of the scanning-head and the time domain fluorescence lifetime imaging detector. Lifetimes from 1.0 to 1.9 nanoseconds were coded in red, representing expected signals from FRET, Fig. 11. Lifetimes from 1.9 to 4.0 nanoseconds were coded in green, representing the expected lifetime of KIF5B-FITC in the absence of acceptor, Fig. 11.

Both the lifetime of KIF5B-FITC in the absence of acceptor or in the presence of an irrelevant acceptor (neurofilament-Cy3) showed a normal distribution with $2.2+/-0.13$ nanoseconds (mean +/- SD) and 2.25 +/- 0.14 nanoseconds, indicative of a lack of FRET, Fig. 12. A strong FRET interaction was observed in untreated neurons co-labeled with $\beta$ tubulin-III-Cy3 and KIF5B-FITC showing a shifted distribution towards shorter lifetimes with a peak value of $1.5+/-0.18$ nanoseconds Fig. 12b. Pre-treatment with TNF- $\alpha$ for 20 minutes abolished the FRET interaction specifically in axons, but not cell bodies, allowing us to recover lifetimes similar to negative controls, Fig. $11 \mathrm{~b}$.

To quantify the effect of TNF- $\alpha$ on the interaction between KIF5B-FITC and $\beta$-tubulinIII-Cy3 we determined the average of the peak lifetimes collected from several regions of interest in the axons, Fig. 12b. In detail, the averaged peak lifetime value in axons was 2.3 +/- 0.5 nanoseconds (mean +/- SD) after 20 minutes TNF- $\alpha$ treatment, while in untreated axons the averaged peak lifetime was $1.5+/-0.18$ nanoseconds, Fig. 12b. Thus, treatment of hippocampal neurons with TNF- $\alpha$ broke apart the molecular interaction between KIF5B and $\beta$-tubulin-III in axons (Fig. 3b). To determine whether the interaction between KIF5B-FITC and $\beta$-tubulin-III-Cy3 in the axons of all cells was affected by TNF- $\alpha$, we analyzed the percentage of axons displaying lifetimes lower than 1.9 nanoseconds. In detail, in untreated neurons 93 +/- $27 \%$ (mean +/- SD) of axons showed shorter lifetimes compatible with FRET, while in TNF treated neurons the percentage of axons showing FRET between KIF5B-FITC and $\beta$-tubulin-III-Cy3 was 
reduced to $4+/-19 \%$ (Fig. 4c). No FRET was observed in the controls by co-labeling KIF5B-FITC and neurofilament-Cy3 of by imaging KIF5B-FITC in the absence of acceptors, Fig. 12.

\subsection{Involvement of JNK phosphorylation in dissociation of KIF5B and $\beta$-tubulin-} III

We then analyzed the involvement of JNK phosphorylation in TNF- $\alpha$ induced breakage

of the molecular interaction between KIF5B and $\beta$-tubulin-III. Hippocampal neurons were treated with TNF- $\alpha$ for 20 minutes and additionally JNK was blocked with the JNK inhibitor SP600125. Cells were co-labeled for KIF5B-FITC and $\beta$-tubulin-III-Cy3. Both confocal fluorescence intensity, Fig. 10 and lifetime images were obtained, Fig. 11c. Additional treatment with the JNK inhibitor reduced the effect of TNF on the molecular interaction between KIF5B and $\beta$-tubulin-III, Fig. 11 and 11. After JNK inhibitor application, the mean lifetime value of KIF5B-FITC of TNF treated neurons was $1.76+$ 0.15 nanoseconds (mean +/- SD) compared to 1.5 +/- 0.18 nanoseconds in neurons treated with TNF- $\alpha$ alone, Fig. 12. After inhibition of JNK, low lifetimes were again detected in $60+/-19 \%$ (mean +/- SD) of axons of TNF- $\alpha$ plus JNK inhibitor treated neurons, while reduced lifetimes were observed in $4+/-19 \%$ of axons in neurons treated with TNF- $\alpha$ alone, Fig. 12.

\subsection{Inhibition of axonal mitochondrial transport by TNF- $\alpha$ via JNK phosphorylation}

The motor protein KIF5B has been shown to be essential for axonal mitochondrial transport [78]. To study whether TNF- $\alpha$ disturbs axonal transport of mitochondria, we transfected cultured hippocampal neurons with a mitochondrial targeting sequence tagged with enhanced yellow fluorescent protein (YFP). To achieve low levels of expression we expressed this mitochondria marker under a neuron-specific synapsin I promoter. The neurons showed expression of YFP in mitochondria starting from day 2-3 in culture and normal axonal morphology, comparable to untransfected neurons. The YFP signal was specifically localized in structures typical of mitochondria, Fig. 13a. Transfected cultures were placed in a heated chamber and scanned every 20 seconds by confocal microscopy. 
Mitochondria showed anterograde and retrograde movement in axons, which are illustrated in the corresponding kymographs, Fig. 13a. To analyze the movement of mitochondria, we determined the number of moving mitochondria (mobile fraction) and their velocity. In total $20+/-12 \%$ (mean +/- SD) of mitochondria moved anterogradely and $21+/-17 \%$ retrogradely. After treatment with TNF- $\alpha$ for 20 minutes, mitochondria stopped moving. In total, the mobile fraction of mitochondria decreased from $41+/-14 \%$ to $7+/-4 \%$ after treatment with TNF- $\alpha$ for 20 minutes. Both anterograde and retrograde movements were substantially reduced to $3+/-4 \%$ and $4+/-4 \%$, respectively, Fig. $13 \mathrm{~b}$. No change in the velocity in the remaining mobile mitochondria was observed after TNF$\alpha$ treatment. Mitochondria moved anterogradely with a velocity of $0.39+/-0.15 \mu \mathrm{m} / \mathrm{sec}$ (mean $+/-$ SD) and retrogradely with a velocity of $0.39+/-0.19 \mu \mathrm{m} / \mathrm{sec}$ in untreated. neurons. In neurons treated with TNF- $\alpha$ for 20 mins, they traveled anterogradely with a velocity of $0.36+/-0.17 \mu \mathrm{m} / \mathrm{sec}$ and retrogradely with a velocity of $0.35+/-0.19 \mu \mathrm{m} / \mathrm{sec}$, Fig. 12c. Inhibition of axonal transport by TNF was mediated via JNK phosphorylation. In detail, after co-treatment of neurons with TNF- $\alpha$ for 20 minutes and the generalized JNK inhibitor $45+/-9 \%$ of mitochondria were mobile, very similar to the untreated situation, in which $41+/-14 \%$ of mitochondria were mobile. Both anterograde and retrograde movements were regained in TNF treated axons after JNK inhibition to $23+/-$ $10 \%$ and $22+/-12 \%$ respectively, Fig. 13b. The inhibitory effect of TNF- $\alpha$ on axonal movement of mitochondria was not long lasting. Already 360 minutes after treatment with TNF- $\alpha$, axons again showed an increased percentage of moving mitochondria, Fig. $13 b$.

\subsection{Inhibition of axonal synaptophysin transport by TNF-a via JNK phosphorylation}

To study whether TNF- $\alpha$ inhibits synaptophysin transport in axons, we transfected cultured hippocampal neurons with synaptophysin tagged with GFP and performed FRAP analysis of a $20 \mu \mathrm{m}$ long axonal segment, Fig. 14a. The mobile fraction and the half-time value $t \frac{1}{2}$ of the fluorescence recovery curve were determined as characteristics of the movement. At 20 minutes and 30 minutes after treatment of neurons with TNF- $\alpha$, a 
significant reduction in the axonal transport of synaptophysin-GFP was detected as determined by FRAP, Fig. 14. In detail, the relative FRAP intensity at 300 seconds was reduced from $0.32+/-0.14$ (mean $+/-\mathrm{SD}$ ) to $0.11+/-0.04$ after 20 minutes treatment with TNF- $\alpha$ Fig. 14b. At 360 minutes after treatment with TNF- $\alpha$, the value returned back to levels comparable to untreated neurons. Furthermore, there was a significant decrease in the mobile fraction of synaptophysin-GFP after treatment with TNF- $\alpha$, indicating that TNF- $\alpha$ reduced the percentage of synaptophysin-GFP transported along the axon. The mobile fraction of synaptophysin-GFP decreased from $39+/-14 \%$ (mean $+/-$ SD) to $13+/-4 \%$ after 20 minutes treatment with TNF- $\alpha$, Fig. 14c. The half-time value $t_{1 / 2}$ of the FRAP, which is correlated to the velocity of synaptophysin-EGFP, was unchanged and not modulated by TNF- $\alpha$ treatment, Fig. 14d. Inhibition of JNK completely neutralized the effect of TNF- $\alpha$ on axonal movement of synaptophysin-GFP. Blockade of JNK in TNF- $\alpha$ treated axons resulted in a mobile fraction of $46+/-21 \%$, while axons treated with TNF- $\alpha$ alone showed a mobile fraction of synaptophysin-GFP of $13+/-4 \%$, Fig. $14 c$. 


\section{DISCUSSION}

\subsection{Analysis of directed movement with FRAP method}

Novel biophysical techniques were applied to study the motility of synaptophysin-EGFP and synaptotagmin I-EGFP in axons. The FRAP method is based on measurement of the net increase in fluorescence signal of a bleached segment.

Detailed analysis of FRAP showed that in unchallenged axons, approximately $30-40 \%$ of the labeled vesicle precursors are immobile either due to directed motion ceasing or formation of presynaptic-like structures. The NO donor and TNF- $\alpha$ had a major effect on the immobile fraction, which increased up to $80 \%$, while the effect on $t \frac{1}{2}$ reflecting the velocity of the movement was not significantly changed after 5-10 minutes of NO donor or TNF- $\alpha$ treatment. These data clearly demonstrate that these cytokines inhibit the net movement of labeled vesicle precursors by increasing the number of immobile particles.

\subsection{Effects of microglia/NO/ TNF- $\alpha$ on neurites}

Microglial cells are activated and highly motile in inflammatory and degenerative brain diseases. In pathological situations they directly interact with neurons and could bind and ensheathe naked or demyelinated axons $[4,79,80]$ in cerebral ischemia. In this study, NO produced by microglia is capable of inhibiting axonal motility of synaptophysinEGFP. It is tempting to speculate that prolonged blockade of axonal transport by NO might injure the axon and induce degeneration although in this study we used a donor which gives a short-term pulse of NO, rather than a promulgated release of NO.

Nitric oxide (NO) is produced in the brain by three isoforms of NO synthase, neuronal (nNOS, type I), endothelial (eNOS, type III) and inducible (iNOS, type II). Nitric oxide participates in diverse physiological brain processes including brain development, pain perception, neuronal plasticity, memory and behavior [81-84]. Furthermore, NO donors added to recombinant synaptic proteins blocked the interaction of n-secl with syntaxin 1a, while it promoted that of VAMP/SNAP-25/syntaxin 1a through induction of disulfide linkages [85], indicating the importance of this molecule in regulating fine processes in the vesicle cycle.

In this study, no evidence for involvement of neuronal NOS in modulation of axonal 
transport was observed. Treatment of neurons with high concentrations of aminoguanidine (2 mM), Fig. 4, which inhibits both iNOS and nNOS, did not modulate the relative FRAP or mobile/immobile fraction. However, this study concentrated on axonal locations and it cannot be excluded that nNOS acts at the presynaptic site, its major location, on transport of synaptic vesicle precursors. While we showed a pathologic action of NO released by activated microglia, one can speculate that NO derived from nNOS might act under physiological situations at the axonal terminal to detach synaptophysin containing precursor vesicles from the motor protein KIF1a or tubulin.

TNF is preferentially produced by activated glial cells, microglia, and astrocytes during brain injury or inflammatory processes [86]. For instance, TNF- $\alpha$ protein has been localized in glial cells after experimental autoimmune encephalomyelitis [87].

TNF- $\alpha$ protein was also detected in neurons by immunohistochemistry after mechanical [88] or ischemic brain injury [89]. Furthermore, TNF- $\alpha$ gene transcription and protein production have been observed during development in total brain tissue extracts [89]. In culture, astrocytes secrete TNF- $\alpha$ at low levels, but cytokine secretion is strongly increased after treatment with inflammatory stimuli such as IFN-gamma combined with IL- $\beta 1$ [90]. TNF- $\alpha$ is produced as a propeptide, which integrates into the cell membrane as a stable homotrimer or can be clipped off at the transmembrane domain by the metalloproteinase TNF- $\alpha$ converting enzyme TACE, [91]. The biological activity of TNF- $\alpha$ is mediated via either the TNFRI (p55 TNF receptor, CD120a) or the TNFRII (p75 TNF receptor, CD120b), which have overlapping functions.

In this study, TNF- $\alpha$ stimulated phosphorylation of JNK in axons. Reduced motility of synaptophysin-EGFP and synaptotagmin-EGFP after TNF- $\alpha$ treatment was dependent on phosphorylation of JNK as determined by the JNK inhibitor SP600125.

\subsection{Mitochondrial tracking}

Unlike the vesicle precursors labeled by synaptophysin-EGFP and synaptotagmin IEGFP, which are widely supposed to be transported by the KIF1A, multiple strands of evidence suggest that mitochondrial movement is mediated by KIF5B [78].

To study whether the acute impairment of axonal transport after exposure to 
inflammatory mediators is a general phenomenon, individual mitochondria were genetically labeled and tracked in living axons. Here, as one can clearly identify individual mitochondria, the velocity of these particles could be directly measured, whilst collecting data on mobile and immobile fractions.

We found that mitochondrial transport was affected in an identical manner to synaptic vesicle precursor transport. In unchallenged neurons, approximately $60 \%$ of mitochondria are immobile (Fig. 14). Within five minutes of exposure to TNF- $\alpha$, this number increases to $93 \%$ of all mitochondria. This effect is transient, possibly as the culture can metabolize TNF- $\alpha$, so that 6 hours after exposure to TNF- $\alpha$, normal levels of transport are restored (Fig. 14).

The acute effect of TNF- $\alpha$ at five minutes of exposure can be blocked by pre-incubating neuronal cultures with decoy receptor, indicating the effect's specificity for TNF- $\alpha$. Consistent with the experiments performed with labeled synaptic vesicle precursors, the effect of TNF- $\alpha$ on mitochondrial transport was blocked by pre-incubation of culture with the JNK inhibitor (Fig. 13).

Also in this experiment, the velocity of the remaining mobile cargo is unchanged (Fig. 15). Intriguingly, both anterograde and retrograde transport is inhibited by TNF- $\alpha$ in a JNK-dependent manner. Whilst we and others have some concrete evidence linking JNK signaling to kinesin scaffolds, much less is known about dynein (which is the canonical retrograde motor) and its adaptor proteins [50]. However recent evidence links the JIP scaffold proteins to the dynein motor protein as well [76]. It is tempting to speculate that a similar mechanism is also at play for retrograde transport, and that transient transport stoppage is a common response to an inflammatory milleu.

We then wished to investigate the molecular mechanism in more detail. It is known that TNF- $\alpha$ can induce changes in cytoskeletal structures [92]. It is suggested that the stimulation of apoptosis by cytoskeletal inhibitors may be attributed to the altered distribution of cell organelles, especially mitochondria. [92].

However, as we observed that the velocity of moving cargoes remained constant in all of our experiments, we found it unlikely that the microtubulae were modified by TNF- $\alpha$ (or indeed, NO) exposure on a short timescale. Rather, we believe that the motor protein, or its cargo, is directly modulated by JNK signaling stimulated by inflammation. 


\subsection{Molecular mechanism, JNK}

To look at conformational changes in the kinesin-microtubule complex directly, we employed the FRET technique in neurons.

Our results allow several crucial insights into the mechanisms regulating axonal transport. First, we demonstrate that TNF- $\alpha$ breaks apart the molecular interaction between KIF5B and tubulin via JNK phosphorylation selectively in axons, but not cell bodies. Thus, JNK not only forms a complex with kinesin and JIP, but also appears to directly modulate the function of kinesin. Second, our data show that TNF- $\alpha$ inhibits anterograde and retrograde axonal movement of mitochondria via JNK phosphorylation. Third, we demonstrate that TNF- $\alpha$ impairs axonal movement of synaptophysin via JNK phosphorylation. Thus, JNK-mediated effects on the kinesin-tubulin complex after TNF$\alpha$ application has important functional consequences leading to impairment in axonal transport of mitochondria and synaptic vesicle precursors.

Primarily, JNKs have been suggested to sense axonal injury and participate in the initiation of the axonal injury response [50]. JNKs are rapidly activated within the axons following nerve injury and can be transported on microtubules along the axon via their association with motor proteins of the kinesin family [50].

The JNK pathway would therefore be an attractive candidate as a sensor of the axonal injury response and regulator of axonal transport [76]. Furthermore, activation of JNK along the length of the axon has also been reported in a mouse model of type-I diabetes, probably representing a danger-signaling system for nerves [95]. In the case of mechanical damage occurring upon nerve injury, JNK was locally phosphorylated at the site of injury [96] and retrograde signals involving JNK support nerve survival and regeneration $[97,98]$. In addition, JNK may have downstream axoplasmic substrates and play an active role in cytoskeletal function. Particularly, JNK1 phosphoryated the microtubule-associated protein 2 [99] and was a dominant regulator of the dendritic architecture [100]. In this study we concentrated on the axon and demonstrated that JNK activation has local axonal effects on the motor machinery in response to the proinflammatory cytokine TNF- $\alpha$. Our data suggest that JNK acts on the motor machinery, but not on the axonal cytoskeleton since the velocity of the mitochondria and 
synaptophysin remaining motile was not altered after JNK stimulation via TNF- $\alpha$ treatment.

JNKs are linked to the kinesin motor proteins via JIPs. Two approaches led to the discovery of the JIPs as kinesin-binding proteins. Bowman et al. [48] performed a genetic screen in Drosophila and identified JIP3 (Sunday Driver, SYD) as interactor of kinesin. Verhey et al. [50] identified JIP1, JIP2 and JIP3 as kinesin protein binding partners by co-immunoprecipitation. The indirect linkage of motors, JNK and cargo via the JIP scaffolding proteins would allow JNK to act as signal transducers to regulate motor activity. Principally, JNK kinases might phosphorylate either kinesin itself or an associated protein, thereby inactivating the motor and leading to dissociation of kinesin from tubulin. We now demonstrated that lifetime-based FRET analysis can be applied in primary neurons to analyze the interaction between tubulin and motor proteins on a subcellular level [56]. Particularly, alterations of the kinesin-tubulin complex after TNF- $\alpha$ treatment were observed in the axons, but not in the cell bodies. Therefore, classical techniques such as immunoprecipitation are not ideally suited to study these interactions. Likewise, we failed to see a clear effect of TNF- $\alpha$ in immunoprecipitation on the molecular interaction between tubulin and kinesin. Principally, the FRET data are consistent with either a change in the conformation of the kinesin-tubulin complex or a complete detachment of kinesin from the microtubules. However, the characteristic increase in the immobile fraction without interference in the velocity of the remaining mobile particles indicates that the kinesin complex dissociates from the microtubules. Particularly, immobile kinesin, which would bind in an 'off' confirmation to tubulin, would act as an obstacle for the remaining mobile particles leading to reduced velocity. As this is not the case, it is indicative that the path of moving mitochondria and synaptophysin is not obstructed at all and immobile mitochondria and synaptophysin containing precursor vesicles are likely to dissociate from tubulin after JNK stimulation by TNF- $\alpha$.

Previously, it was shown that TNF- $\alpha$ induced perinuclear clustering of mitochondria in fibroblasts via the TNF receptor I [101]. It was suggested that TNF- $\alpha$ acted via hyperphosphorylation of kinesin light chain and inhibited the kinesin-mediated transport of mitochondria [102]. Thus, TNF- $\alpha$ appears to act on the kinesin motor complex in 
several cell types. Perinuclear clustering of mitochondria was also evident in mice with targeted disruption of the conventional kinesin heavy chain KIF5B [78]. The mitochondrial dislocation was reversed by exogenous expression of KIF5B [78] indicating that KIF5B is required for plus end-directed transport of mitochondria along microtubules. Our data now link mitochondrial movement and conformational change in KIF5B via TNF- $\alpha$-induced JNK phosphorylation. Furthermore, we demonstrated that TNF- $\alpha$-induced JNK phosphorylation inhibits synaptophysin transport. Synaptophysin is produced at the cell body, integrated into synaptic vesicle precursors and then anterogradely transported along axons [103]. Defects in axonal transport of synaptophysin containing vesicle precursors have been observed in KIF1A mutant mice. Thus, the JNK signaling pathway appears to be widely involved in axonal transport of organelles and vesicular structures.

Very little is known about the regulation of vesicle transport and detachment of vesicles from tubulin in axons. Synaptic precursor vesicles containing synaptophysin are connected to the kinesin motor protein KIF 1a via scaffolding proteins of the JSAP1/JIP3 family [49]. The JIP family associates with JNK and JNK kinases, which appear to be responsible for the regulation of the vesicle movement by modulating the attachment and detachment of the vesicle to the kinesin motors [49]. In principal both NO and TNF- $\alpha$ could directly act on the JNK or JNK kinases, which have been shown to be modulated by S-nitrosylation [104]. In case of NO it might also act on the kinesin motors, which have essential cysteins at their binding sites to tubulin. However, NO treated neurons inhibited by JNK were again wild-type suggesting NO acts indirectly on kinesin motor protein via JNK. 


\section{CONCLUSION}

The data demonstrate that $\mathrm{NO}$ and TNF- $\alpha$ released by activated microglia inhibit directed axonal movement of synaptic precursor vesicles containing synaptophysin or synaptotagmin I. In a collaborating laboratory, this data was confirmed by directly measuring the velocity of labeled precursors using the FCS (fluorescence correlation spectroscopy) technique. In these experiments, labeled precursors traveled at velocities well comparable with published values, and the fraction of immobile vesicles was strongly increased by treatment with NO.

This data was also confirmed by mitochondrial tracking experiments, where we clearly demonstrate that TNF $\alpha$ transiently but strongly impaired the transport of mitochondria and that this phenomenon is mediated via the JNK pathway. Interestingly, the velocity of these cargoes was not affected by TNF- $\alpha$ treatment. This suggests the protein complexes driving the vesicle are dynamically regulated by signal transduction pathways with a common nexus over the JNK protein.

We demonstrate that JNK is associated with a complex containing $\beta$ III tubulin and the motor protein KIF5B. Finally, FRET experiments showed that the direct interaction between conventional kinesin KIF5b and $\beta$ III tubulin is abrogated by exposure to TNF$\alpha$, and that it could be restored by pre-inhibition of JNK signalling.

These results allow us to construct a model, where JNK incorporated in the scaffold of motor proteins causes the detachment of the motor protein from tubulin upon exposure to an inflammatory signaling. Those motor proteins unaffected by active JNK are thus able to be transported at normal velocities.

Another implication raised by our model is that now we began to understand the fine and complex link between inflammation (particularly activated microglia) and neuronal axonal transport, suggesting a future point for therapeutical intervention. 


\section{REFERENCES}

1. Neumann, H., Molecular mechanisms of axonal damage in inflammatory central nervous system diseases. Curr. Opin. Neurol., 2003. 16: p. 267-273.

2. Selkoe, D.J., Alzheimer's Disease Is a Synaptic Failure. Science, 2002. 298: p. 789-791.

3. Bitsch, A., Schuchardt, J., Bunkowski,S., Kuhlmann,T., and Bruck,W., Acute axonal injury in multiple sclerosis. Correlation with demyelination and inflammation. Brain, 2000. 123: p. 1174-1183.

4. Peterson, J.W., Bo,L., Mork,S., Chang,A., and Trapp,B.D., Transected neurites, apoptotic neurons, and reduced inflammation in cortical multiple sclerosis lesions. Ann. Neurol., 2001. 50: p. 389-400.

5. Medana, I.M., Day,N.P., Hien,T.T., Mai,N.T., Bethell,D., Phu,N.H., Farrar,J., Esiri,M.M., White,N.J., and Turner,G.D., Axonal Injury in Cerebral Malaria. Am. J. Pathol., 2002. 160: p. 655-666.

6. McGlade-McCulloh, E., Morrissey,A.M., Norona,F., and Muller,K.J., Individual microglia move rapidly and directly to nerve lesions in the leech central nervous system. Proc. Natl. Acad. Sci. U. S. A, 1989. 86: p. 1093-1097.

7. Oehmichen, M., Theuerkauf,I., and Meissner,C., Is traumatic axonal injury (AI) associated with an early microglial activation? Application of a double-labeling technique for simultaneous detection of microglia and AI. Acta Neuropathol. (Berl), 1999. 97: p. 491-494.

8. Trapp, B.D., Peterson,J., Ransohoff,R.M., Rudick,R., Mork,S., and Bo,L., Axonal transection in the lesions of multiple sclerosis. N. Engl. J. Med, 1998. 338: p. 278-285.

9. Raja, F., Sherriff,F.E., Morris,C.S., Bridges,L.R., and Esiri,M.M., Cerebral white matter damage in HIV infection demonstrated using beta- amyloid precursor protein immunoreactivity. Acta Neuropathol. (Berl), 1997. 93: p. 184-189.

10. Gentleman, S.M., Nash,M.J., Sweeting,C.J., Graham,D.I., and Roberts,G.W., Beta-amyloid precursor protein (beta APP) as a marker for axonal injury after head injury. Neurosci. Lett, 1993. 160: p. 139-144.

11. Pendlebury, S.T., Lee,M.A., Blamire,A.M., Styles,P., and Matthews,P.M., Correlating magnetic resonance imaging markers of axonal injury and demyelination in motor impairment secondary to stroke and multiple sclerosis. Magn Reson. Imaging, 2000. 18: p. 369-378.

12. Yonekawa, Y., Harada,A., Okada,Y., Funakoshi,T., Kanai,Y., Takei,Y., Terada,S., Noda,T., and Hirokawa,N., Defect in synaptic vesicle precursor transport and neuronal cell death in KIF1A motor protein-deficient mice. J. Cell Biol., 1998. 141: p. 431-441.

13. Goldstein, L.S., Do disorders of movement cause movement disorders and dementia? Neuron, 2003. 40(2): p. 415-25.

14. Kreutzberg, G.W., Microglia: a sensor for pathological events in the CNS. Trends Neurosci, 1996. 19(8): p. 312-8.

15. Iliev, A., Stringaris,A.K., Nau,R., and Neumann,H., Neuronal injury mediated via stimulation of microglial toll-like receptor-9 (TLR9). FASEB J. Express, 2003. 
16. Del-Rio Hortega, P., Cytology and Cellular Pathology of the Nervous System. Trends Neurosci, 1932: p. 481-534.

17. V. Hugh Perrya, P.-B.A.a.S.G., Macrophages and inflammation in the central nervous system. Trends Neurosci., 1993. 16: p. 268-273.

18. Ling, E.A.W., W C, The origin and nature of ramified and amoeboid microglia: $a$ historical review and current concepts. Glia, 1993. 7(1): p. 9-18.

19. W.F. Hickey, K.V.a.H.L., Bone marrow-derived elements in the central nervous system: An immunohistochemical and ultrastructural survey of rat chimeras. J. Neuropathol. Exp. Neurol., 1992. 51: p. 246-256.

20. Fedoroff, S., Neuroglia. Neuroglia, 1995. 162-181.

21. J. Gehrmann, e.a., Brain Pathol, 1993. 3: p. 11-18.

22. Jochen Gehrmann, a., Yoh Matsumotob and Georg W. Kreutzbergc, Microglia: Intrinsic immuneffector cell of the brain. Brain Res, 1995: p. 269-287.

23. W.J. Streit, M.B.G.a.G.W.K., Functional plasticity of microglia: a review. Glia, 1988: p. 301-307.

24. D.W. Dickson, e.a., Microglia in human disease, with an emphasis on acquired immune deficiency syndrome. Lab. Invest, 1991(64): p. 135-156.

25. McGeer P.L., I.S.M.E.G., Expression of the histocompatibility glycoprotein HLADR in neurological disease. ACTA NEUROPATHOL., 1988. 76(6): p. 550-557.

26. Merzbacher, L., Fischer Verlag, Untersuchungen über die Morphologie und Biologie der Abräumzellen im Zentralnervensystem. 1909.

27. Banati, R.B.G., J; Schubert, P; Kreutzberg, G W, Cytotoxicity of microglia. Glia, 1993. 7(1): p. 111-118.

28. Gilbert., C.A.C.a.D.L., Production of superoxide anions by a CNS macrophage, the microglia. FEBS Lett., 1987. 223: p. 284-288.

29. Banati, R.B.R., G; Valet, G; Kreutzberg, G W, Detection of lysosomal cysteine proteinases in microglia: flow cytometric measurement and histochemical localization of cathepsin B and L. Glia, 1993. 7(2): p. 183-191.

30. Thery C., C.B., Mallat M., Cytotoxic effect of brain macrophages on developing neurons. EUR. J. NEUROSCI., 1991. 3(11): p. 1155-1164.

31. Stagi M, D.P., Frank N, Iliev AI, Schwille P, Neumann H., Breakdown of axonal synaptic vesicle precursor transport by microglial nitric oxide. J Neurosci., 2005. 25(2): p. 352-62.

32. Goldstein, L.S. and Z. Yang, Microtubule-based transport systems in neurons: the roles of kinesins and dyneins. Annu Rev Neurosci, 2000. 23: p. 39-71.

33. Hirokawa, N., Organelle transport along microtubules - the role of KIFs. Trends Cell Biol, 1996. 6(4): p. 135-41.

34. Hirokawa, N., Y. Noda, and Y. Okada, Kinesin and dynein superfamily proteins in organelle transport and cell division. Curr Opin Cell Biol, 1998. 10(1): p. 6073.

35. Okada, Y., Yamazaki,H., Sekine-Aizawa,Y., and Hirokawa,N., The neuronspecific kinesin superfamily protein KIF1A is a unique monomeric motor for anterograde axonal transport of synaptic vesicle precursors. Cell, 1995. 81: p. 769-780.

36. Lin, R.C. and R.H. Scheller, Mechanisms of synaptic vesicle exocytosis. Annu Rev Cell Dev Biol, 2000. 16: p. 19-49. 
37. Janz, R., et al., Essential roles in synaptic plasticity for synaptogyrin I and synaptophysin I. Neuron, 1999. 24(3): p. 687-700.

38. Fernandez-Chacon, R., et al., Analysis of SCAMP1 function in secretory vesicle exocytosis by means of gene targeting in mice. J Biol Chem, 1999. 274(46): p. 32551-4.

39. Wang, G.J., J.G. Jackson, and S.A. Thayer, Altered distribution of mitochondria impairs calcium homeostasis in rat hippocampal neurons in culture. $\mathrm{J}$ Neurochem, 2003. 87(1): p. 85-94.

40. McFadden, G.I. and S.A. Ralph, Dynamin: the endosymbiosis ring of power? Proc Natl Acad Sci U S A, 2003. 100(7): p. 3557-9.

41. Boyer, P.D., The ATP synthase--a splendid molecular machine. Annu Rev Biochem, 1997. 66: p. 717-49.

42. Pedersen, P.L., ATP synthase. The machine that makes ATP. Curr Biol, 1994. 4(12): p. 1138-41.

43. Safiulina, D., et al., Loss of mitochondrial membrane potential is associated with increase in mitochondrial volume: Physiological role in neurones. J Cell Physiol, 2005.

44. Ligon, L.A. and O. Steward, Movement of mitochondria in the axons and dendrites of cultured hippocampal neurons. J Comp Neurol, 2000. 427(3): p. 34050 .

45. Mallik, R. and S.P. Gross, Molecular motors: strategies to get along. Curr Biol, 2004. 14(22): p. R971-82.

46. Kural, C., et al., Kinesin and dynein move a peroxisome in vivo: a tug-of-war or coordinated movement? Science, 2005. 308(5727): p. 1469-72.

47. Byrd, D.T., Kawasaki,M., Walcoff,M., Hisamoto,N., Matsumoto,K., and Jin,Y., UNC-16, a JNK-signaling scaffold protein, regulates vesicle transport in $C$. elegans. Neuron, 2001. 32: p. 787-800.

48. Bowman, A.B., et al., Kinesin-dependent axonal transport is mediated by the sunday driver (SYD) protein. Cell, 2000. 103(4): p. 583-94.

49. Byrd, D.T., et al., UNC-16, a JNK-signaling scaffold protein, regulates vesicle transport in C. elegans. Neuron, 2001. 32(5): p. 787-800.

50. Verhey, K.J., et al., Cargo of kinesin identified as JIP scaffolding proteins and associated signaling molecules. J Cell Biol, 2001. 152(5): p. 959-70.

51. Inomata, H., et al., A scaffold protein JIP-1b enhances amyloid precursor protein phosphorylation by JNK and its association with kinesin light chain 1. J Biol Chem, 2003. 278(25): p. 22946-55.

52. Kamal, A., et al., Kinesin-mediated axonal transport of a membrane compartment containing beta-secretase and presenilin-1 requires APP. Nature, 2001.

414(6864): p. 643-8.

53. Davis, R.J., Signal transduction by the JNK group of MAP kinases. Cell, 2000. 103(2): p. 239-52.

54. Reits, E.A. and J.J. Neefjes, From fixed to FRAP: measuring protein mobility and activity in living cells. Nat Cell Biol, 2001. 3(6): p. E145-7.

55. Stagi, M., et al., Breakdown of axonal synaptic vesicle precursor transport by microglial nitric oxide. J Neurosci, 2005. 25(2): p. 352-62. 
56. Wallrabe, H. and A. Periasamy, Imaging protein molecules using FRET and FLIM microscopy. Curr Opin Biotechnol, 2005. 16(1): p. 19-27.

57. Lakowicz, J.R., Energy transfer. In Principles of Fluorescence Spectroscopy. 1999. 2nd ed. Plenum: p. 367-394.

58. Bacskai, B.J., Skoch, J., Hickey, G.A., Allen, R., Hyman, B.T., Fluorescence resonance energy transfer determinations using multiphoton fluorescence lifetime imaging microscopy to characterize amyloid-beta plaques. J Biomed Opt, 2003.

8: p. 368-375.

59. O. Berezovska, B.J.B., and B. T. Hyman, Monitoring Proteins in Intact Cells. Sci. Aging Knowl. Environ, 2003. 23: p. 14 - 14.

60. M. Tramier, I.G., T. Piolot, S. Ravalet, K. Kemnitz, J. Coppey, C. Durieux, V. Mignotte, and M. Coppey-Moisan, Picosecond-Hetero-FRET Microscopy to Probe Protein-Protein Interactions in Live Cells. Biophys. J, December 1, 2002. 83(6): p. 3570 - 3577.

61. Becker, W., K. Benndorf, A. Bergmann, C. Biskup, K. König, U. Tirlapur, and T. Zimmer, FRET measurements by TCSPC laser scanning microscopy. Proc. SPIE, 2001. 4431: p. 414-419.

62. Neumann, H., et al., Tumor necrosis factor inhibits neurite outgrowth and branching of hippocampal neurons by a rho-dependent mechanism. J Neurosci, 2002. 22(3): p. 854-62.

63. Kugler, S., Kilic,E., and Bahr,M., Human synapsin 1 gene promoter confers highly neuron-specific long-term transgene expression from an adenoviral vector in the adult rat brain depending on the transduced area. Gene Ther, 2003. 10: p. 337-347.

64. Kaether, C., Skehel,P., and Dotti,C.G., Axonal membrane proteins are transported in distinct carriers: a two-color video microscopy study in cultured hippocampal neurons. Mol. Biol. Cell, 2000. 11(1213-1224).

65. Neumann, H., Misgeld,T., Matsumuro,K., and Wekerle,H., Neurotrophins inhibit major histocompatibility class II inducibility of microglia: involvement of the p75 neurotrophin receptor. Proc. Natl. Acad. Sci. U. S. A, 1998. 95: p. 5779-5784.

66. Axelrod, D., D. E. Koppel, J. Schlessinger, E. Elson, and W. W. Webb, Mobility measurement by analysis of fluorescence photobleaching recovery kinetics. Biophys. J, 1976. 16: p. 1055-1069.

67. Förster, T., Delocalized excitation and excitation transfer. In Modern Quantum Chemistry-Istanbul Lectures, Part III (O. Sinano lu, ed.), 1965: p. 93-137.

68. Gadella, T.W., Jr. and T.M. Jovin, Oligomerization of epidermal growth factor receptors on A431 cells studied by time-resolved fluorescence imaging microscopy. A stereochemical model for tyrosine kinase receptor activation. $\mathrm{J}$ Cell Biol, 1995. 129(6): p. 1543-58.

69. Chen, Y. and A. Periasamy, Characterization of two-photon excitation fluorescence lifetime imaging microscopy for protein localization. Microsc Res Tech, 2004. 63(1): p. 72-80.

70. Köllner, M.W., J., How many photons are necessary for fluorescence-lifetime measurements? Chem. Phys. Lett., 1992. 200: p. 199-204.

71. Maragos, C.M., Morley,D., Wink,D.A., Dunams,T.M., Saavedra,J.E., Hoffman,A., Bove,A.A., Isaac,L., Hrabie,J.A., and Keefer,L.K., Complexes of NO 
with nucleophiles as agents for the controlled biological release of nitric oxide.Vasorelaxant effects. J. Med. Chem, 1991. 34: p. 3242-3247.

72. Ahern, G.P., V.A. Klyachko, and M.B. Jackson, cGMP and S-nitrosylation: two routes for modulation of neuronal excitability by NO. Trends Neurosci, 2002.

25(10): p. 510-7.

73. Go, Y.M., et al., Evidence for peroxynitrite as a signaling molecule in flowdependent activation of c-Jun NH(2)-terminal kinase. Am J Physiol, 1999. 277(4 Pt 2): p. H1647-53.

74. Taimor, G., Rakow,A., and Piper,H.M., Transcription activator protein 1 (AP-1) mediates NO-induced apoptosis of adult cardiomyocytes. FASEB J, 2001. 15: p. 2518-2520.

75. Park, H.S., et al., Nitric oxide negatively regulates $c$-Jun $\mathrm{N}$-terminal kinase/stressactivated protein kinase by means of S-nitrosylation. Proc Natl Acad Sci U S A, 2000. 97(26): p. 14382-7.

76. Goldstein, L.S., Transduction. When worlds collide--trafficking in JNK. Science, 2001. 291(5511): p. 2102-3.

77. Muresan, Z. and V. Muresan, c-Jun NH2-terminal kinase-interacting protein-3 facilitates phosphorylation and controls localization of amyloid-beta precursor protein. J Neurosci, 2005. 25(15): p. 3741-51.

78. Tanaka, Y., et al., Targeted disruption of mouse conventional kinesin heavy chain, kif5B, results in abnormal perinuclear clustering of mitochondria. Cell, 1998. 93(7): p. 1147-58.

79. McGlade-McCulloh, E., et al., Individual microglia move rapidly and directly to nerve lesions in the leech central nervous system. Proc Natl Acad Sci U S A, 1989. 86(3): p. 1093-7.

80. Peterson, J.W., et al., Transected neurites, apoptotic neurons, and reduced inflammation in cortical multiple sclerosis lesions. Ann Neurol, 2001. 50(3): p. 389-400.

81. Ahern, G.P., Klyachko,V.A., and Jackson,M.B., cGMP and S-nitrosylation: two routes for modulation of neuronal excitability by NO, in Trends Neurosci. 2002. p. 510-517.

82. Dawson, T.M.a.S., S.H., Gases as biological messengers: nitric oxide and carbon monoxide in the brain. J. Neurosci, 1994. 14(5147-5159).

83. Lipton, S.A., Choi,Y.B., Pan,Z.H., Lei,S.Z., Chen,H.S., Sucher,N.J., Loscalzo,J., Singel,D.J., and Stamler,J.S., A redox-based mechanism for the neuroprotective and neurodestructive effects of nitric oxide and related nitroso-compounds. Nature, 1993. 364: p. 626-632.

84. Melino, G., Bernassola,F., Knight,R.A., Corasaniti,M.T., Nistico,G., and FinazziAgro,A., S-nitrosylation regulates apoptosis. Nature, 1997. 388: p. 432-433.

85. Meffert, M.K., Calakos,N.C., Scheller,R.H., and Schulman,H., Nitric oxide modulates synaptic vesicle docking fusion reactions. Neuron, 1996. 16: p. 12291236.

86. Hopkins, S.J.a.N.J.R., Cytokines and the Nervous System I: expression and recognition. TINS, 1995. 18(2): p. 83-88.

87. Renno, T., et al., TNF-alpha expression by resident microglia and infiltrating leukocytes in the central nervous system of mice with experimental allergic 
encephalomyelitis. Regulation by Th1 cytokines. J Immunol, 1995. 154(2): p. 94453.

88. Tchelingerian, J.L., et al., Localization of TNF alpha and IL-1 alpha immunoreactivities in striatal neurons after surgical injury to the hippocampus. Neuron, 1993. 10(2): p. 213-24.

89. Bruce, A.J., et al., Altered neuronal and microglial responses to excitotoxic and ischemic brain injury in mice lacking TNF receptors. Nat Med, 1996. 2(7): p. 788-94.

90. Chung, I.Y., and E. N. Benveniste., TNF produced by astrocytes induced by lipopolysaccharide, interferon- and interleukin-1ß. J. Immunol., 1990. 144: p. 2999-3007.

91. Blobel, C.P., Metalloprotease-disintegrins: links to cell adhesion and cleavage of TNF alpha and Notch. Cell, 1997. 90(4): p. 589-92.

92. Domnina, L.V., et al., Effects of the inhibitors of dynamics of cytoskeletal structures on the development of apoptosis induced by the tumor necrosis factor. Biochemistry (Mosc), 2002. 67(7): p. 737-46.

93. Puig, B., et al., Expression of stress-activated kinases $\mathrm{c}$-Jun $\mathrm{N}$-terminal kinase (SAPK/JNK-P) and p38 kinase (p38-P), and tau hyperphosphorylation in neurites surrounding betaA plaques in APP Tg2576 mice. Neuropathol Appl Neurobiol, 2004. 30(5): p. 491-502.

94. Savage, M.J., et al., Activation of c-Jun N-terminal kinase and p38 in an Alzheimer's disease model is associated with amyloid deposition. J Neurosci, 2002. 22(9): p. 3376-85.

95. Middlemas, A., et al., Enhanced activation of axonally transported stressactivated protein kinases in peripheral nerve in diabetic neuropathy is prevented by neurotrophin-3. Brain, 2003. 126(Pt 7): p. 1671-82.

96. Cavalli, V., et al., Sunday Driver links axonal transport to damage signaling. J Cell Biol, 2005. 168(5): p. 775-87.

97. Kenney, A.M. and J.D. Kocsis, Peripheral axotomy induces long-term c-Jun amino-terminal kinase-1 activation and activator protein-1 binding activity by cJun and junD in adult rat dorsal root ganglia In vivo. J Neurosci, 1998. 18(4): p. 1318-28.

98. Raivich, G., et al., The AP-1 transcription factor $c$-Jun is required for efficient axonal regeneration. Neuron, 2004. 43(1): p. 57-67.

99. Chang, L., et al., JNK1 is required for maintenance of neuronal microtubules and controls phosphorylation of microtubule-associated proteins. Dev Cell, 2003. 4(4): p. 521-33.

100. Bjorkblom, B., et al., Constitutively active cytoplasmic c-Jun N-terminal kinase 1 is a dominant regulator of dendritic architecture: role of microtubule-associated protein 2 as an effector. J Neurosci, 2005. 25(27): p. 6350-61.

101. De Vos, K., et al., The 55-kDa tumor necrosis factor receptor induces clustering of mitochondria through its membrane-proximal region. J Biol Chem, 1998. 273(16): p. 9673-80.

102. De Vos, K., et al., Tumor necrosis factor induces hyperphosphorylation of kinesin light chain and inhibits kinesin-mediated transport of mitochondria. J Cell Biol, 2000. 149(6): p. 1207-14. 
103. Hirokawa, N., Kinesin and dynein superfamily proteins and the mechanism of organelle transport. Science, 1998. 279(5350): p. 519-26.

104. Hall, J.P., E. Merithew, and R.J. Davis, c-Jun N-terminal kinase (JNK) repression during the inflammatory response? Just say NO. Proc Natl Acad Sci U S A, 2000. 97(26): p. 14022-4. 


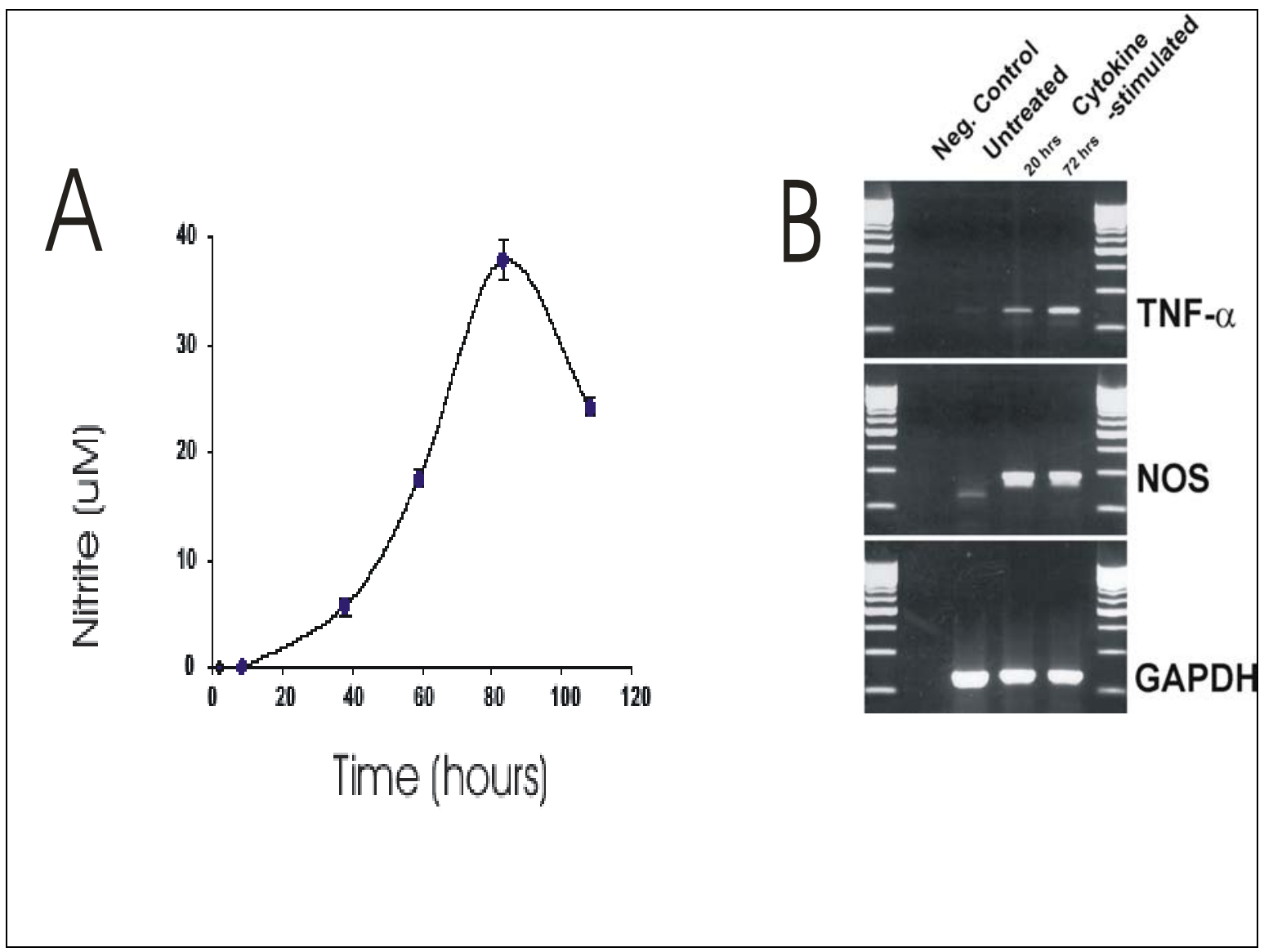

Fig 1. NO release by cytokine-stimulated microglia. (a) Measurement of NO released in the supernatant of cultured microglia at distinct time periods after combined cytokine $(10 \mathrm{ng} / \mathrm{ml} \mathrm{IL-1} \beta$ and $100 \mathrm{U} / \mathrm{ml} \mathrm{IFN-} \gamma$ for 72 hours) stimulation. To measure the release of NO from microglial cells the Griess Reagent System (Promega) was used. The system was calibrated with a standard curve. The detection limit was $2.5 \mu \mathrm{M}$ nitrite. (b) Detection of inducible NO synthase (iNOS) gene transcripts in microglia stimulated by the cytokines IFN- $\gamma(100 \mathrm{U} / \mathrm{ml})$ and IL-1 $\beta(10 \mathrm{ng} / \mathrm{ml})$ for 72 hours. Gene transcripts for GAPDH were amplified by RTPCR as control. RT-PCR was performed by 30 cycles of amplification with the following primers for iNOS, TNF-alpha and GAPDH: iNOS ( 5'-AAGCTGCATGTGACATCGAC-3' ; 5'TGCTGAAACATTTCCTGTGC-3' ），TNF （ 5-GGGGTGATCGGTCCCCAAAGG-3 ; 5CGGGGCAGCCTTGTCCCTTG-3 ) ; and glyceraldehyde-3-phosphate dehydrogenase (GAPDH) ( 5'TCCGCCCCTTCTGCCGATG-3' ; 5'- CACGGAAGGCCATGCCAGTGA-3' ). 


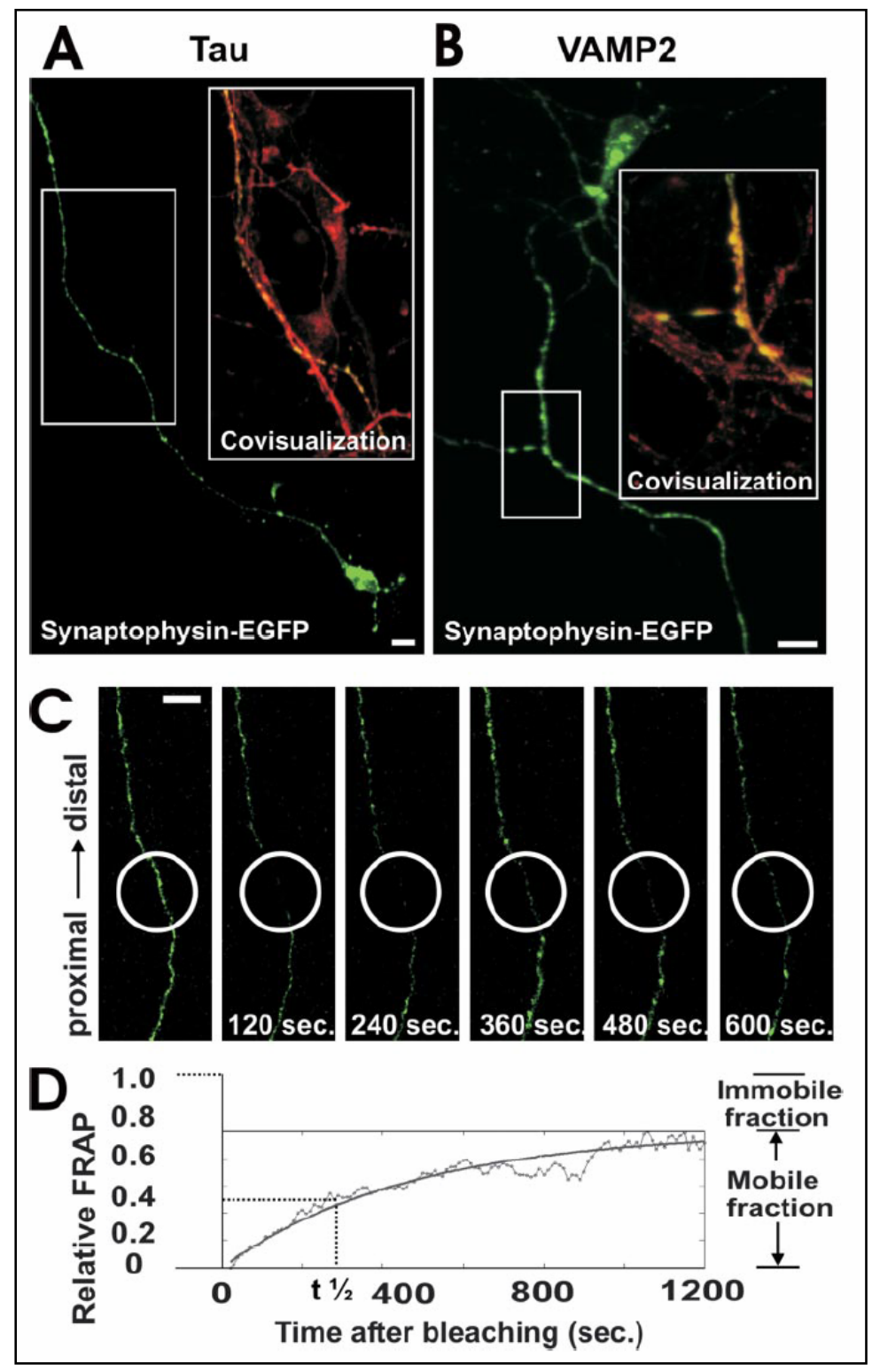

Fig 2. Axonal expression and FRAP analysis of synaptophysin-EGFP. $a$, Neuron transfected with synaptophysin-EGFP (green) and immunolabeled with antibodies directed against tau (red). Synaptophysin-EGFP is localized in the axon. Area selected for inset as indicated. Scale bar, $10 \mathrm{~m} . b$, Neuron transfected with synaptophysin-EGFP (green) and immunolabeled with an antibody directed against VAMP2 (red). Colocalization between synaptophysin-EGFP and VAMP2 demonstrates expression of synaptophysin-EGFP in synaptic vesicle precursors. Area selected for inset as indicated. Scale bar, $10 \mathrm{~m}$. $c$, FRAP of an axon from a synaptophysin-EGFP-transfected neuron. The bleached area of 20 min length (white circle) was scanned by confocal microscopy over time, and fluorescence recovery intensity was determined. Selected images before bleaching and 120, 240, 360, 480, and $600 \mathrm{sec}$ after bleaching are shown. Scale bar, $10 \mathrm{~m}$. $d$, Relative FRAP intensity of synaptophysin-EGFP in an axon that was time-lapse scanned over $1200 \mathrm{sec}$. Individual values of each $10 \mathrm{sec}$ and the curve of the equation are shown. 


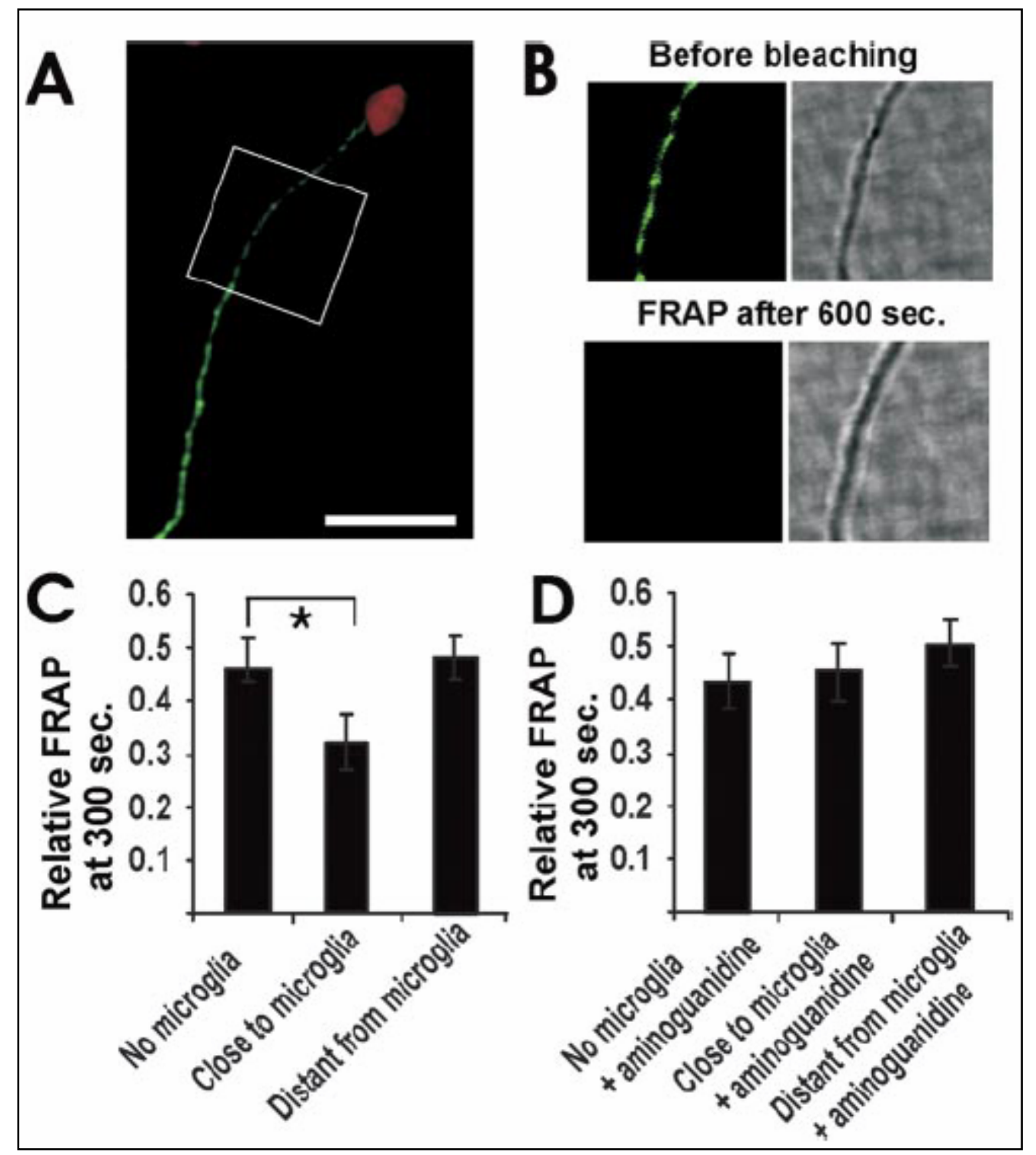

Fig 3. Impaired axonal movement of synaptophysin-EGFP near cytokine-stimulated microglia. $a$, Cultured hippocampal neurons were transfected with synaptophysin-EGFP. Axon of a neuron transfected with synaptophysin-EGFP (green) and challenged with cytokine-stimulated microglia (red) is shown. Area of FRAP analysis as indicated. Scale bar, $20 \mathrm{~m}$. $b$, Fluorescence and transmission images from an axon of a neuron transfected with synaptophysin-EGFP (green) and challenged with a cytokine-stimulated microglia (see area of FRAP analysis in A). Fluorescence and transmission images before bleaching and $600 \mathrm{sec}$ after bleaching are shown. Total size of images: $2020 \mathrm{~m}$. c, Relative FRAP at $300 \mathrm{sec}$ of axonal segments close to or distant from (50 m distance) microglia prestimulated by the cytokines IFN-(100 U/ml) and IL-1(10 $\mathrm{ng} / \mathrm{ml}$ ) for $72 \mathrm{hr}$. Data are presented as mean $+/$ SD. For each experimental condition, $n=3 .{ }^{*}=p<0.01 . d$, Relative FRAP at $300 \mathrm{sec}$ of axonal segments close to or distant from (50 m distance) a cytokine-stimulated microglial cell. The microglia or the neurons were pretreated with the NO synthase inhibitor aminoguanidine $(2 \mathrm{mM})$. Data are presented as mean $+/$ - SD. For each experimental condition, $n=3$. 


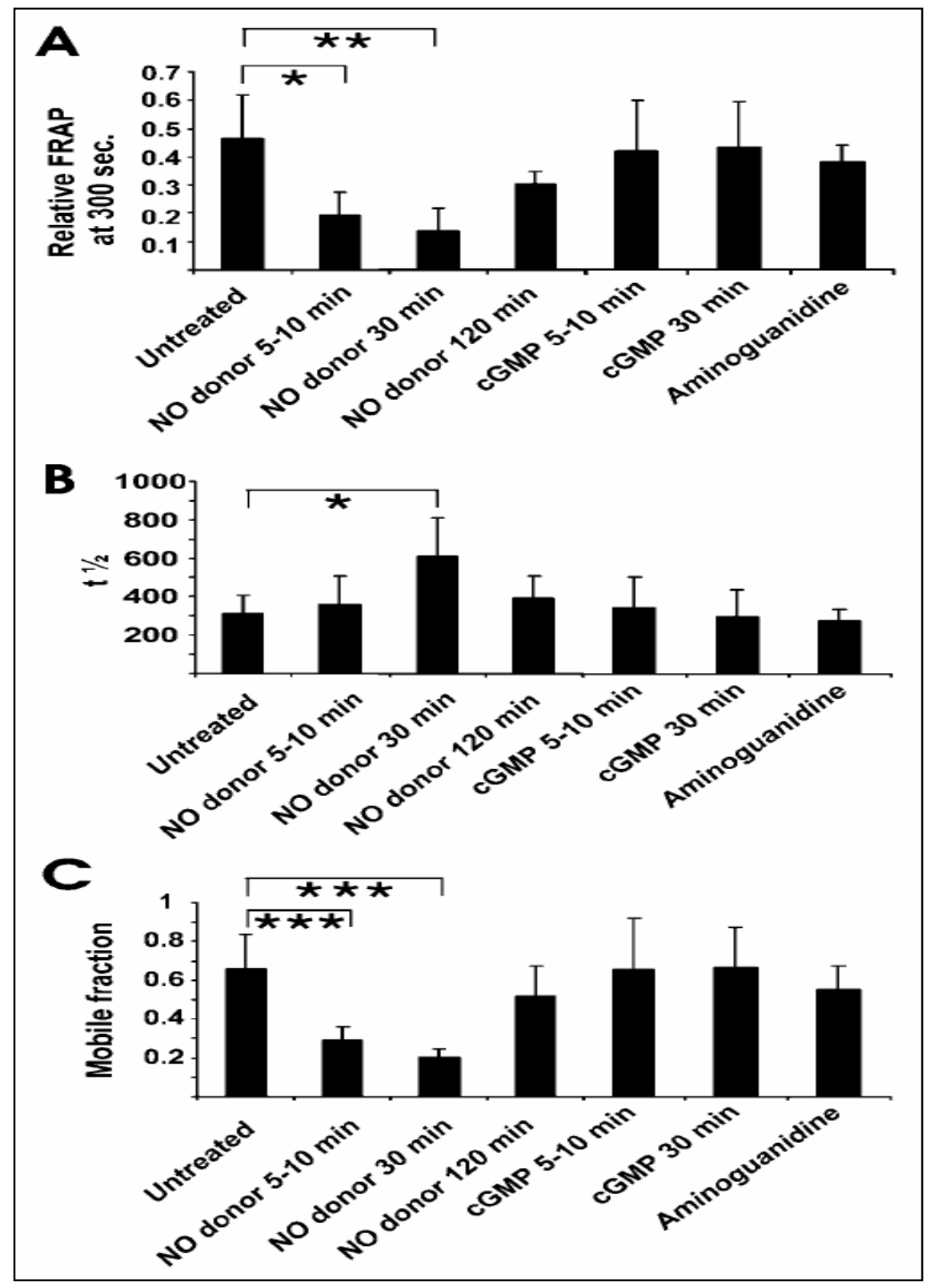

Fig 4. Impaired axonal movement of synaptophysin-EGFP after NO donor application. $a$, Relative FRAP at $300 \mathrm{sec}$ in axons of neurons transfected with synaptophysin-EGFP and treated with NO donor (300 M DEA/NONOate). NO donor treatment reduced the axonal transport of synaptophysin-EGFP. Synaptophysin-EGFP transport was not modulated by cGMP (0.2 $\mathrm{mM}$ 8-bromo-cGMP) or aminoguanidine $(2.5 \mathrm{mM})$ treatment. Data are presented as mean + - SD. For each experimental condition, $n=5$. ${ }^{*} p<0.05$; $* * p<0.005$. $b$, Half-time value $\left(t_{1 / 2}\right)$ of FRAP in axons of neurons transfected with synaptophysin-EGFP. The increase in $t_{1 / 2}$ after $30 \mathrm{~min}$ of $\mathrm{NO}$ donor treatment indicates a decrease in the velocity of synaptophysin-EGFP movement. Data are presented as mean $+/-$ SD. For each experimental condition, $n=5$. ${ }^{*} p<0.05$. $c$, Mobile fraction in axons of neurons transfected with synaptophysin-EGFP. NO donor treatment significantly reduced the percentage of synaptophysin-EGFP moving along the axons. Data are presented as mean $+/$ - SD. For each experimental condition, $n=5$. ${ }^{* * *} p<0.001$. 


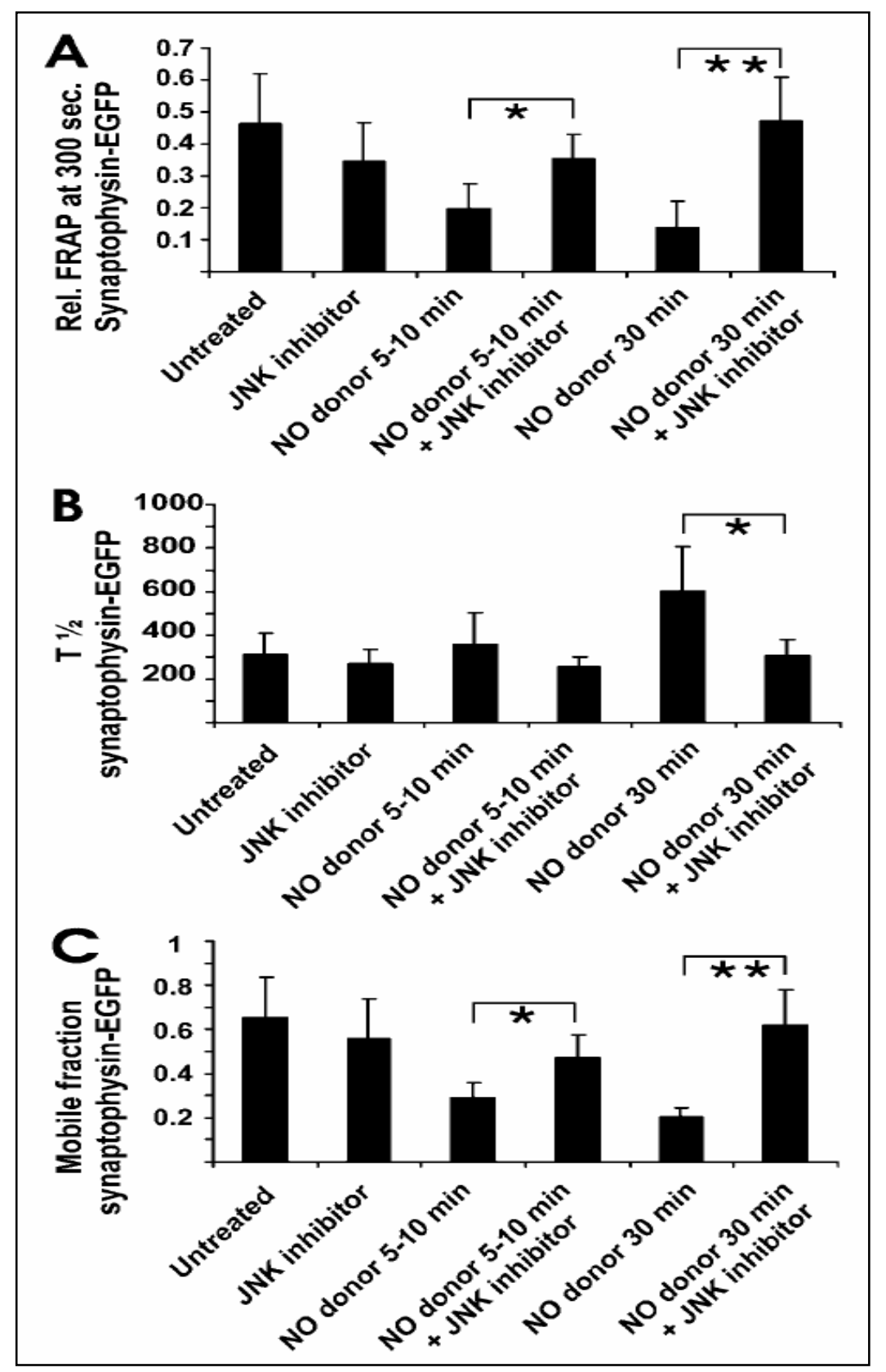

Fig 5. Impaired axonal movement of synaptophysin-EGFP after NO donor application depends on JNK phosphorylation. $a$, Relative FRAP at $300 \mathrm{sec}$ in axons of neurons transfected with synaptophysin-EGFP and treated with NO donor (300 M DEA/NONOate). NO donor treatment reduced the axonal transport of synaptophysin-EGFP. Additional pretreatment with the JNK inhibitor (100 nM JNK inhibitor II) reverted the inhibitory effect of the NO donor on axonal motility. Data are presented as mean SD. For each experimental condition, $n=5$. ${ }^{*} p 0.05 ; * * p 0.005$. $b$, Half-time value $\left(t_{1 / 2}\right)$ of FRAP in axons of neurons transfected with synaptophysin-EGFP. The increase in $t_{1 / 2}$ after $30 \mathrm{~min}$ of NO donor treatment indicates a decrease in the velocity of synaptophysin-EGFP movement. Data are presented as mean SD. For each experimental condition, $n=5 .{ }^{*} p 0.01$. $c$, Mobile fraction of FRAP in axons of neurons transfected with synaptophysin-EGFP. NO donor treatment significantly reduced the percentage of synaptophysin-EGFP moving along the axons. Additional pretreatment with the JNK inhibitor (100nM JNK inhibitorII) reverted the inhibitory effect of the NO donor on the mobile fraction. Data are presented as mean $+/-\mathrm{SD}$. For each experimental condition, $n=5 .{ }^{*} p<0.01 ;{ }^{* *} p<0.005$. 


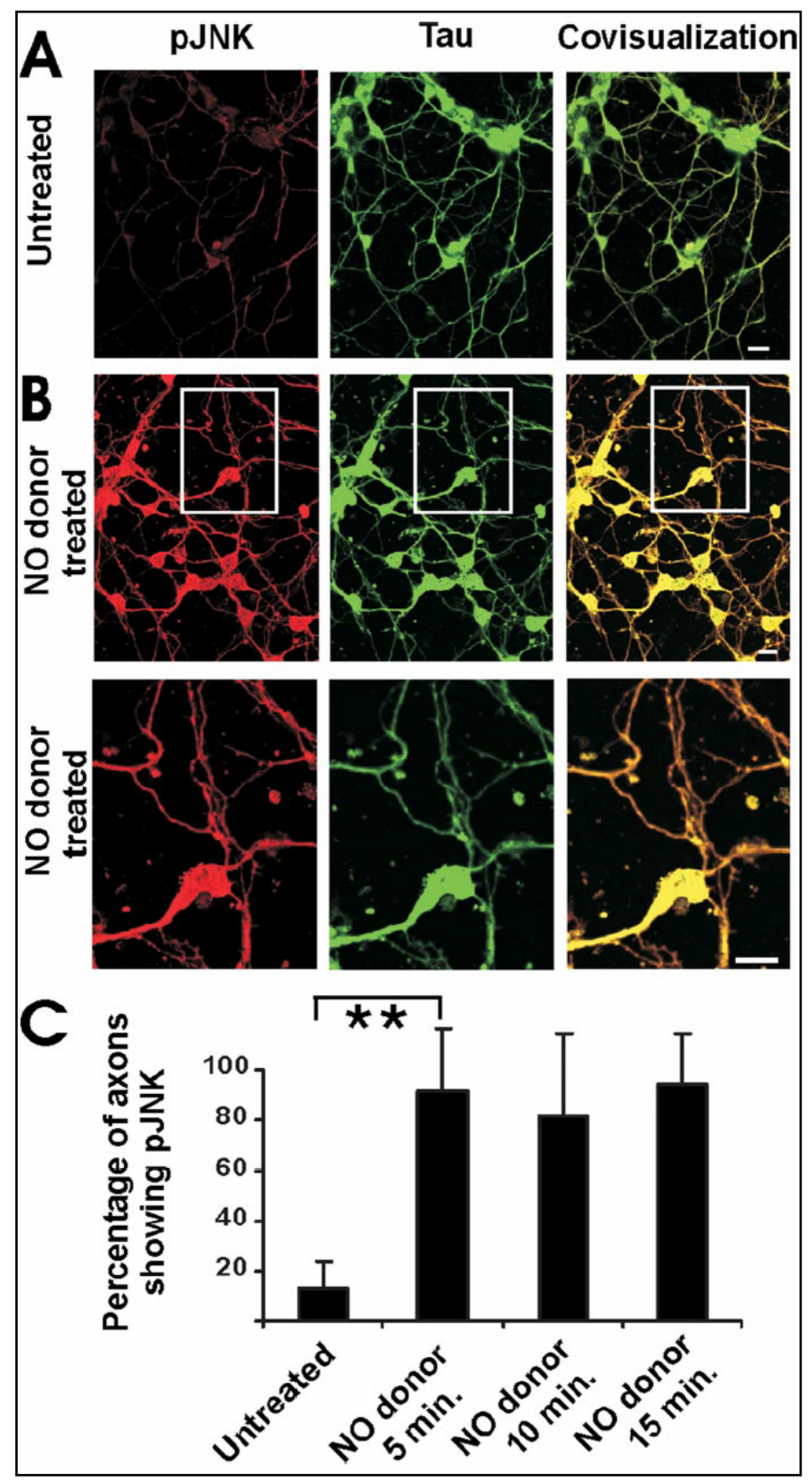

Fig 6. Immunohistochemistry of phosphorylated JNK in cultured hippocampal neurons. $a$, Neurons were identified by antibodies directed against the axonal marker protein tau (green). Only rare punctate staining of phosphorylated JNK (red) was detected in untreated neurons. Scale bar, $10 \mathrm{~m}$. $b$, Phosphorylated JNK (red) was observed in most tau (green)-positive axons after treatment of the cultures with $300 \mathrm{M}$ DEA/NONOate for $5 \mathrm{~min}$. Area selected for inset as indicated. Scale bar, $10 \mathrm{~m}$. c, Percentage of axons identified by immunolabeling with antibodies directed against tau that show double-labeling for phosphorylated JNK. Neurons are either untreated or treated with $300 \mathrm{M}$ DEA/NONOate for 5, 10, or 15 min. Data are presented as mean $+/$ - SEM. $* *=p<0.005$. 


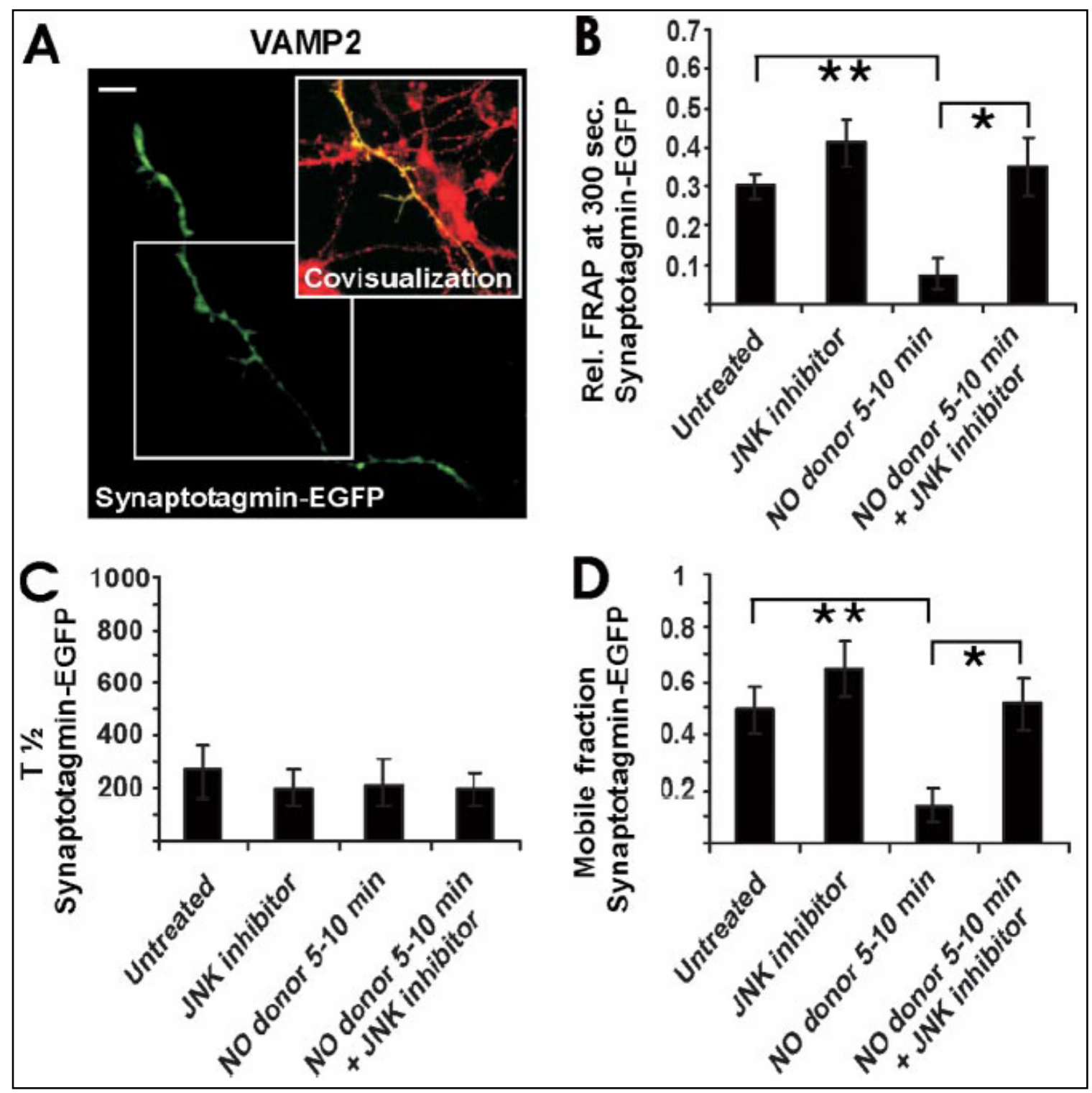

Fig 7. Impaired axonal movement of synaptotagmin-EGFP after NO donor application. $a$, Neuron transfected with synaptotagmin-EGFP (green) and immunolabeled with antibodies directed against VAMP2 (red). Colocalization between synaptotagmin-EGFP and VAMP2 indicates expression of synaptotagmin-EGFP in synaptic vesicle precursors. Area selected for inset as indicated. Scale bar, $10 \mathrm{~m}$. $b$, Relative FRAP at $300 \mathrm{sec}$ in axons of neurons transfected with synaptotagmin-EGFP and treated with NO donor (300 M DEA/NONOate). NO donor treatment reduced the axonal transport of synaptotagmin-EGFP. Additional pretreatment with the JNK inhibitor (100 nM JNK inhibitor II) reverted the inhibitory effect of the NO donor on axonal transport. Data are presented as mean +/- SD. For each experimental condition, $n=4$. $*=p<0.05 ; * *=p<0.005$. $c$, Half-time value $\left(t_{1 / 2}\right)$ of FRAP in axons of neurons transfected with synaptotagmin-EGFP. Data are presented as mean $+/$ - SD. For each experimental condition, $n=4$. $d$, Mobile fraction of FRAP in axons of neurons transfected with synaptotagmin-EGFP. NO donor treatment significantly reduced the percentage of synaptotagmin-EGFP moving along the axons. Additional pretreatment with the JNK inhibitor (100 nM JNK inhibitor II) reverted the inhibitory effect of the NO donor on the mobile fraction. Data are presented as mean $+/-$ SD. For each experimental condition, $n=4$. $*=p<0.05 ; * *=p<0.005$. 


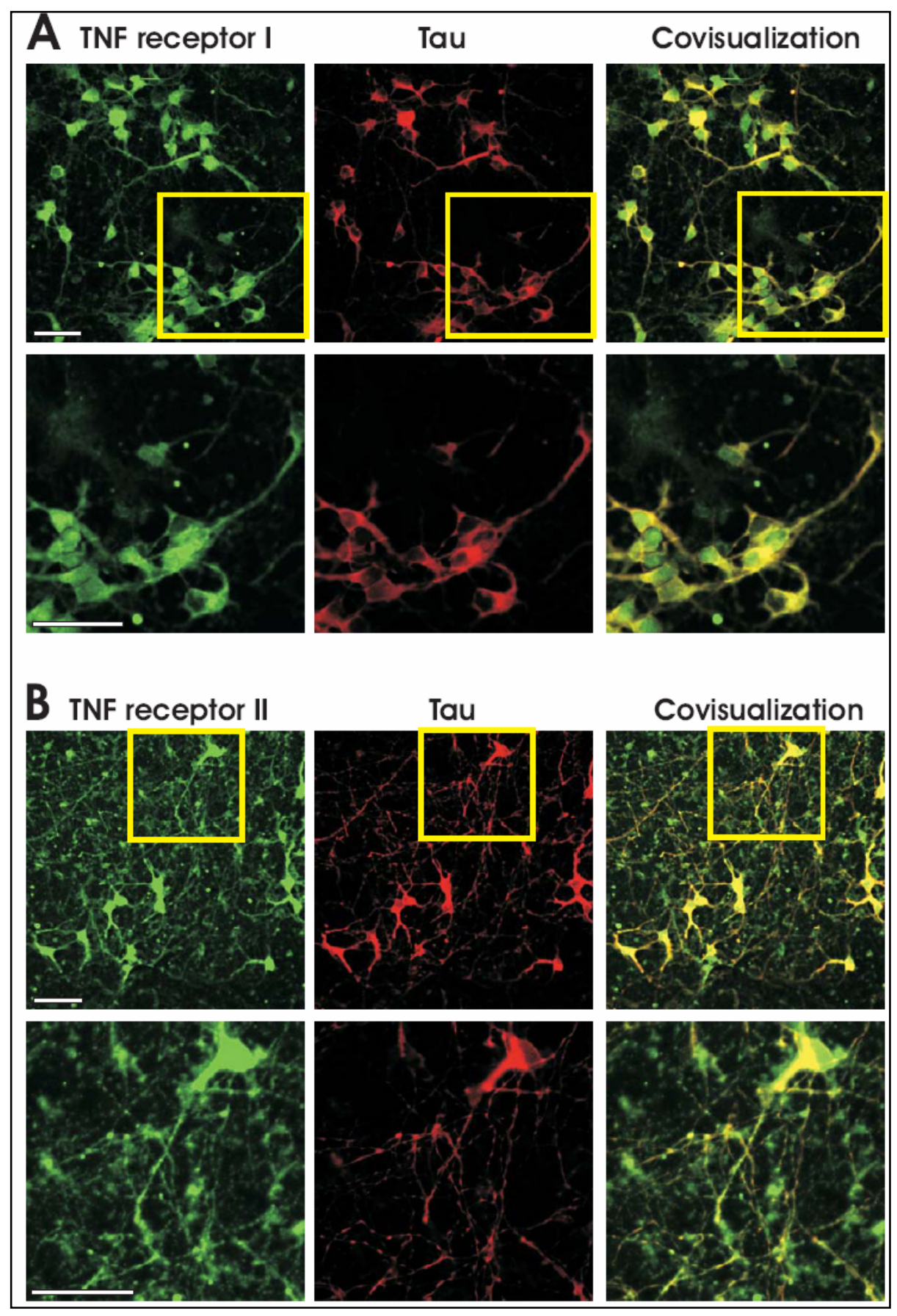

Fig 8. Expression of TNF receptor I and II in axons of cultured neurons.

A.Primary hippocampal neurons were immunolabeled with specific antibodies directed against TNF receptor I (green) and double labeled with specific antibodies directed against the axonal marker protein tau (red). B. Expression of TNF receptor I is detected on tau positive axons. Scale bar: $30 \mu$ m. Primary hippocampal neurons were immunolabeled with specific antibodies directed against TNF receptor II (green) and double labeled with specific antibodies directed against the axonal marker protein tau (red). Expression of TNF receptor II is detected on tau positive axons. Scale bar: $40 \mu \mathrm{m}$. 


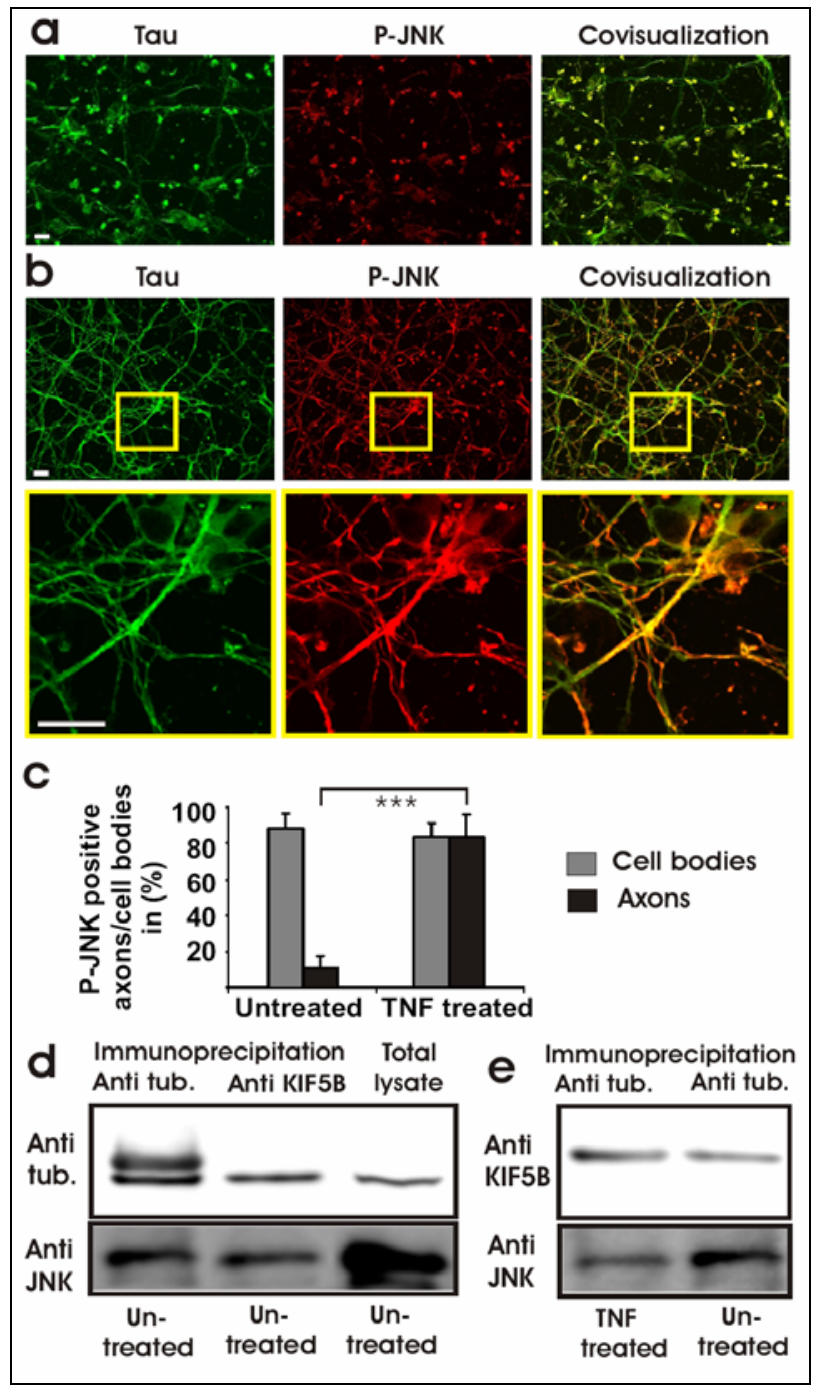

Fig 9. Immunodetection of phosphorylated JNK in axons after TNF- $\alpha$ treatment and complex formation between JNK, KIF5B and $\beta$-tubulin-III.

a. Cultured hippocampal neurons were immunolabeled with specific antibodies directed against phosphorylated JNK (P-JNK; red) and co-labeled with antibodies directed against tau (Tau; green). In untreated neurons phosphorylated JNK was detected in cell bodies, but not in axons. Scale bar: $15 \mu \mathrm{m}$.

b. Following treatment of neurons with TNF- $\alpha$ for 20 minutes strong labeling for phosphorylated JNK was observed in cell bodies and axons. Insets as indicated Scale bars: $20 \mu \mathrm{m}$.

c. Number of axonal processes and cell bodies identified by co-labeling with antibodies directed against tau showing expression of phosphorylated JNK. Neurons were either untreated or treated with TNF- $\alpha$ for 20 minutes. Data are presented as mean $+/-$ SEM. ${ }^{* * *}=\mathrm{p}<0.001$ (two-tailed Mann-Whitney U test).

d. Protein lysates of cultured hippocampal neurons were immunoprecipitated with specific antibodies directed against $\beta$-tubulin-III (Anti tub.) or KIF5B (Anti KIF5B). Immunoprecipitated proteins were analyzed by Western blotting with specific antibodies directed against $\beta$-tubulin-III (Anti tub.) or JNK (Anti JNK). JNK was detected in protein precipitates immunoselected for $\beta$-tubulin-III (Anti tub III) or KIF5B (Anti KIF5B).

e. Protein lysates of cultured hippocampal neurons either untreated or treated with TNF- $\alpha$ for 20 minutes were immunoprecipitated with specific antibodies directed against $\beta$-tubulin-III (Anti tub.). Immunoprecipitated proteins were analyzed by Western blotting with specific antibodies directed against KIF5B (Anti KIF5B) or JNK (Anti JNK). No effect of TNF- $\alpha$ on the complex was observed. 


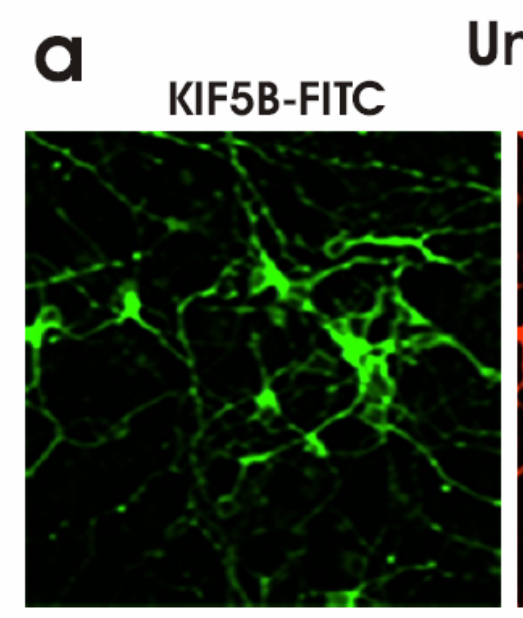

\section{Untreated neurons} Tub III-Cy3
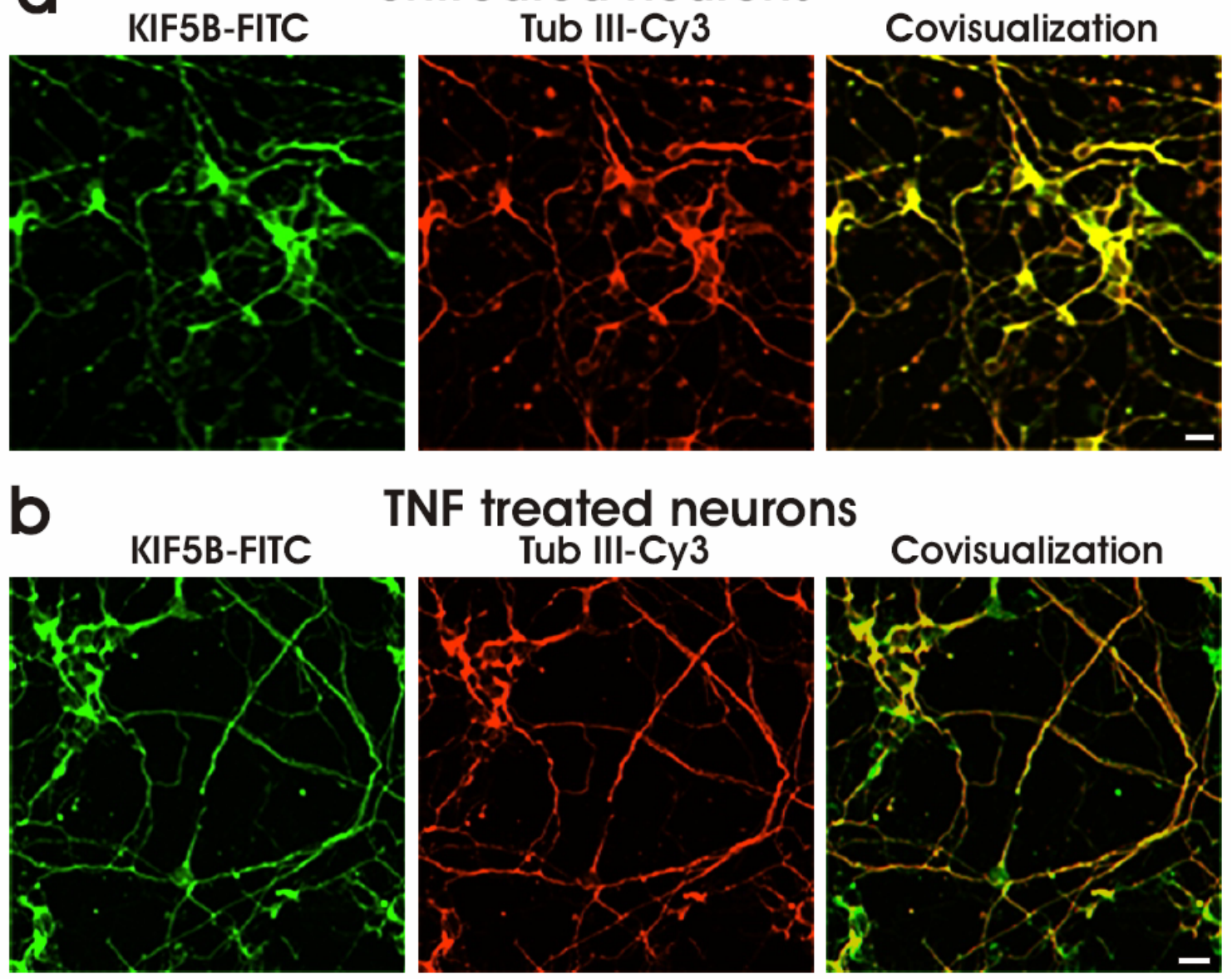

\section{TNF treated neurons} Tub III-Cy3

\section{Covisualization}
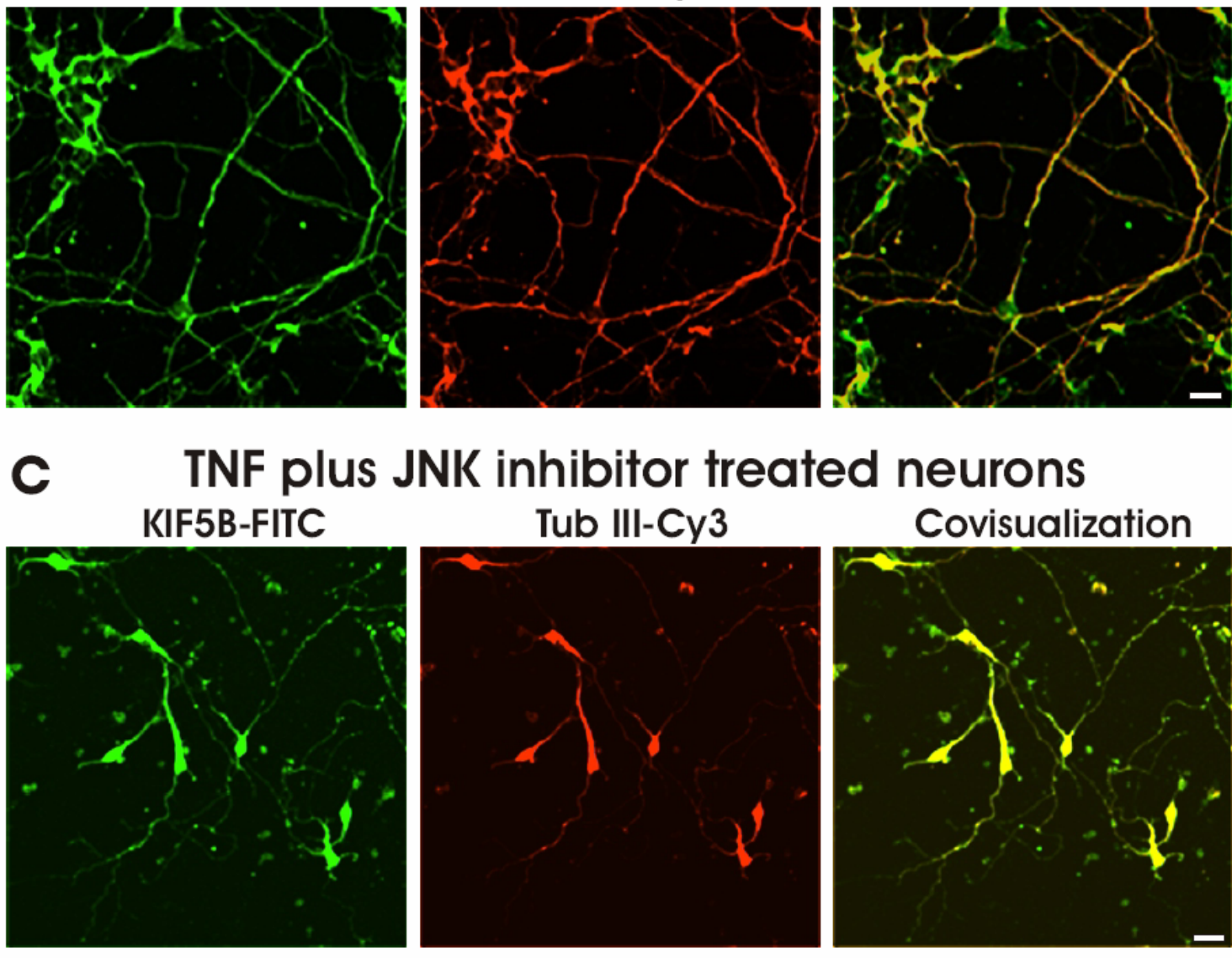

ted neurons

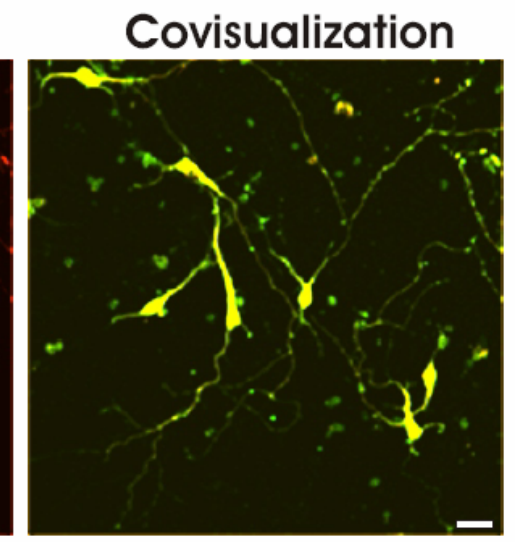

Fig 10. Colocalization of KIF5B and $\beta$-tubulin-III in primary hippocampal neurons by confocal microscopy.

Neurons were co-immunolabeled with antibodies directed against KIF5B marked with FITC and antibodies directed against $\beta$-tubulin-III marked with Cy3. Confocal images for KIF5B-FITC (green) and $\beta$-tubulinIII-Cy3 (red) are shown for untreated cells (a), cells treated for 20 minutes with TNF- $\alpha$ (b) or cells treated with TNF- $\alpha$ for 20 minutes and the JNK inhibitor SP600125 (c). KIF5B co-localized with $\beta$-tubulin-III as determined by confocal microcopy. Scale bars: $20 \mu \mathrm{m}$. 


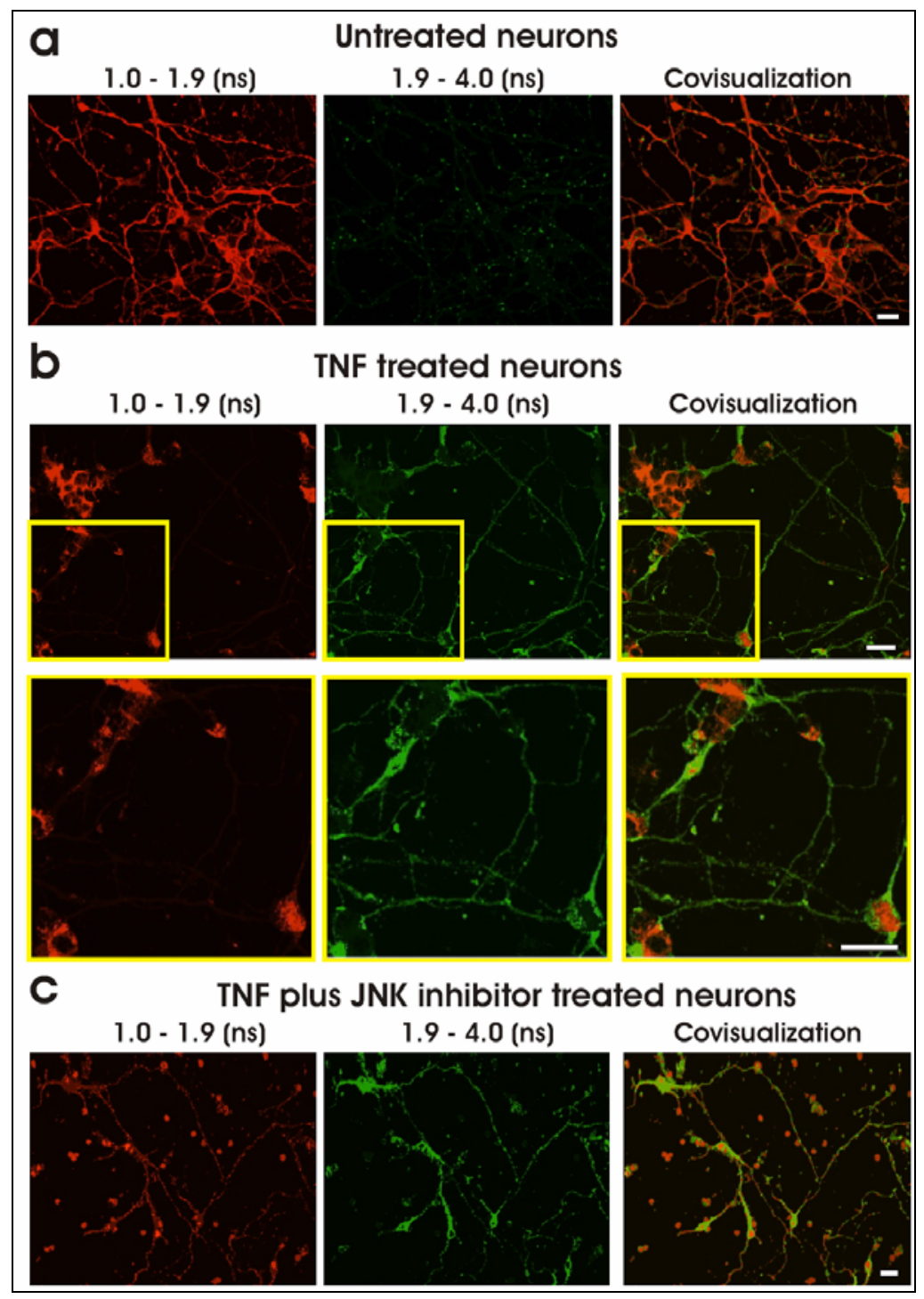

Fig 11. Effects of TNF- $\alpha$ on the molecular interaction between KIF5B and tubulin-III as determined by lifetime based FRET analysis. Neurons were co-immunolabeled with antibodies directed against KIF5B marked with FITC and antibodies directed against $\beta$-tubulin-III marked with Cy3. Two-photon laser scanning single-photon counting lifetime images of KIF5B-FITC were obtained with a Becker-Hickl system. Lifetime images were acquired through a band-pass filter centered at $520 \pm 15 \mathrm{~nm}$ to selectively acquire the FITC spectral band. Acquired lifetime values between 1.0 and 1.9 nanoseconds were coded in red and values between 1.9 and 4.0 nanoseconds were coded in green.

a. In untreated neurons direct association between $\beta$-tubulin-III and KIF5B was observed as demonstrated by lifetime values coded in red. Scale bar: $20 \mu \mathrm{m}$.

b. After treatment with TNF- $\alpha$ for 20 minutes the conformation of the KIF5B- $\beta$-tubulin-III complex changed in axons as demonstrated by lifetime values coded in green. Specifically, TNF- $\alpha$ induced a breakage of the normal KIF5B- $\beta$-tubulin-III complex in axons, but not in cell bodies. Insets as indicated. Scale bars: $20 \mu \mathrm{m}$.

c. After JNK inhibition of TNF- $\alpha$ treated neurons the lifetime values partially reverted to levels comparable to untreated neurons indicating that JNK is involved in the TNF- $\alpha$ mediated changes on KIF5B- $\beta$-tubulinIII complex in axons. Scale bar: $20 \mu \mathrm{m}$. 


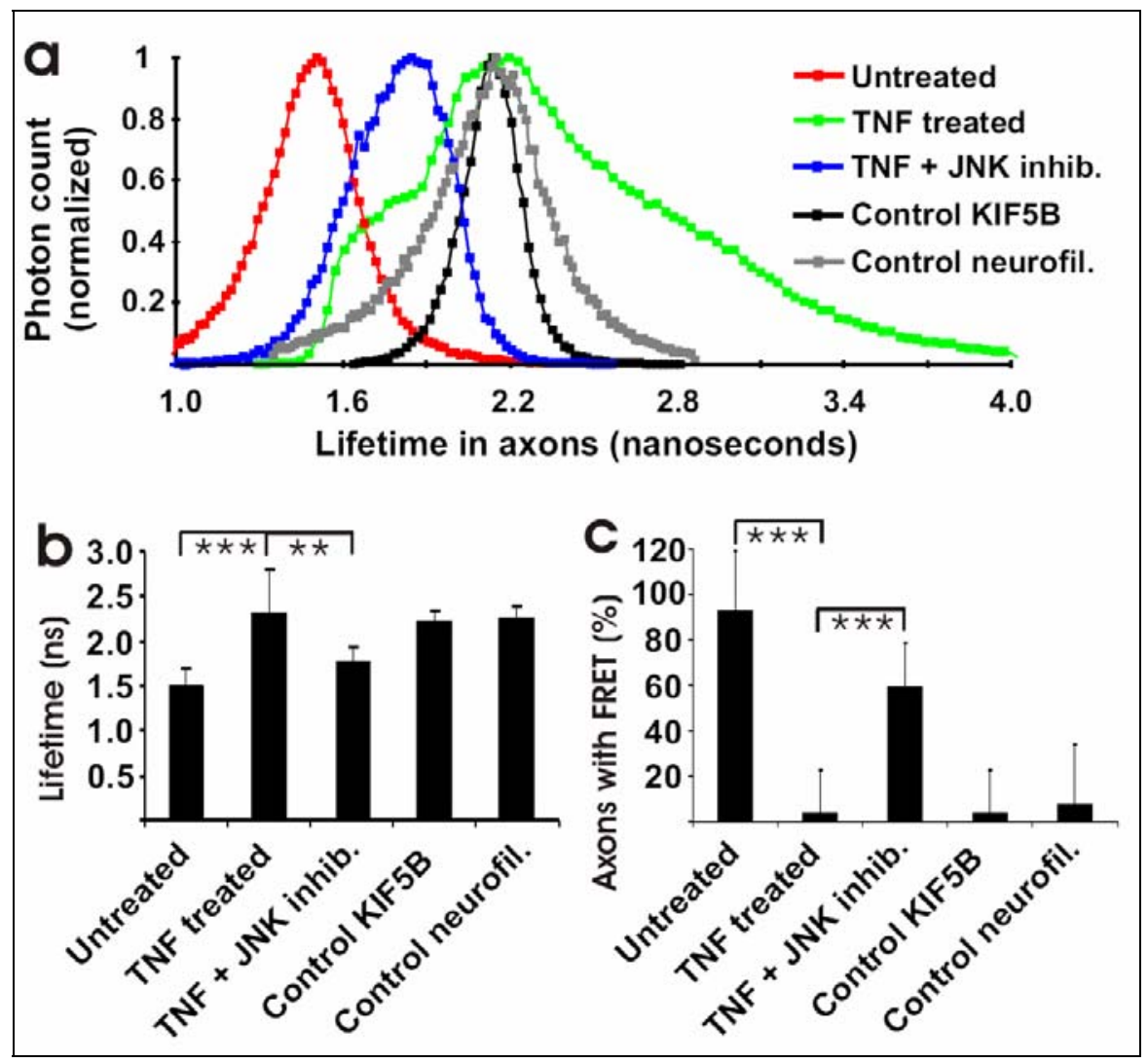

Fig 12. Effects of TNF- $\alpha$ on the molecular interaction between KIF5B and tubulin-III as determined by lifetime based FRET analysis. Neurons were co-immunolabeled with antibodies directed against KIF5B marked with FITC and antibodies directed against $\beta$-tubulin-III marked with Cy3.

a. Lifetime histograms demonstrating a change in the KIF5B- $\beta$-tubulin-III complex after TNF- $\alpha$ treatment dependent on JNK phosphorylation. Untreated neurons (Untreated) co-labeled for KIF5b-FITC and $\beta$ tubulin-III-Cy3 showed a shift of the lifetime distribution of FITC with a peak value of approximately 1.5 nanoseconds compared to neurons (Control neurofilament) co-labeled with KIF5B-FITC and an irrelevant acceptor (neurofilament-Cy3) with a peak value of approximately 2.2 nanoseconds. After treatment with TNF- $\alpha$ for 20 minutes, neurons (TNF treated) co-labeled for KIF5B-FITC and $\beta$-tubulin-III-Cy3 showed a lifetime distribution with a peak value of $2.2+/-0.13$ nanoseconds. TNF + JNK inhib.: Neurons co-labeled for KIF5b-FITC and $\beta$-tubulin-III-Cy3 and treated with TNF- $\alpha$ and JNK inhibitor. Control KIF5B:

Untreated neurons labeled with KIF5B and without acceptor.

b. Analysis of lifetime peak values in axons. Untreated neurons (Untreated) co-labeled for KIF5b-FITC and $\beta$-tubulin-III-Cy3 showed a shift of the lifetime distribution with a mean peak value of $2.3+/-0.5$ nanoseconds (mean $+/-\mathrm{SD}$ ) compared to TNF- $\alpha$ treated neurons (TNF treated) with a mean peak value of $1.5+/-0.18$ nanoseconds or untreated neurons (Control neurofilament) co-labeled with KIF5B-FITC and neurofilament-Cy3 with a mean peak value of $2.25+/-0.14$ nanoseconds. Control KIF5B: Lifetime values of KIF5B after labelling of KIF5B-FITC alone. Data are presented as mean +/- SD. $* * * p<0.001$; ** $\mathrm{p}<0.01$ ( $\mathrm{t}$ test).

c. Analysis of the percentage of axons showing short lifetime as a sign of molecular interaction between KIF5B-FITC and $\beta$-tubulin-III-Cy3. TNF- $\alpha$ treatment (TNF) induced breakage of the KIF5B- $\beta$-tubulin-III complex in almost all axons, while co-treatment of neurons with JNK inhibitor and TNF- $\alpha$ (TNF plus JNK inhib.) prevented the conformational change in the KIF5B- $\beta$-tubulin-III complex. Control neurofilament: Axons showing long lifetime after co-labelling of KIF5B-FITC and neurofilament-Cy3. Control KIF5B: Axons showing long lifetime after labelling of KIF5B-FITC without acceptor alone. Data are presented as mean $+/$ - SD. ${ }^{* * *} \mathrm{p}<0.001$ (Mann Whitney $\mathrm{U}$ test). 


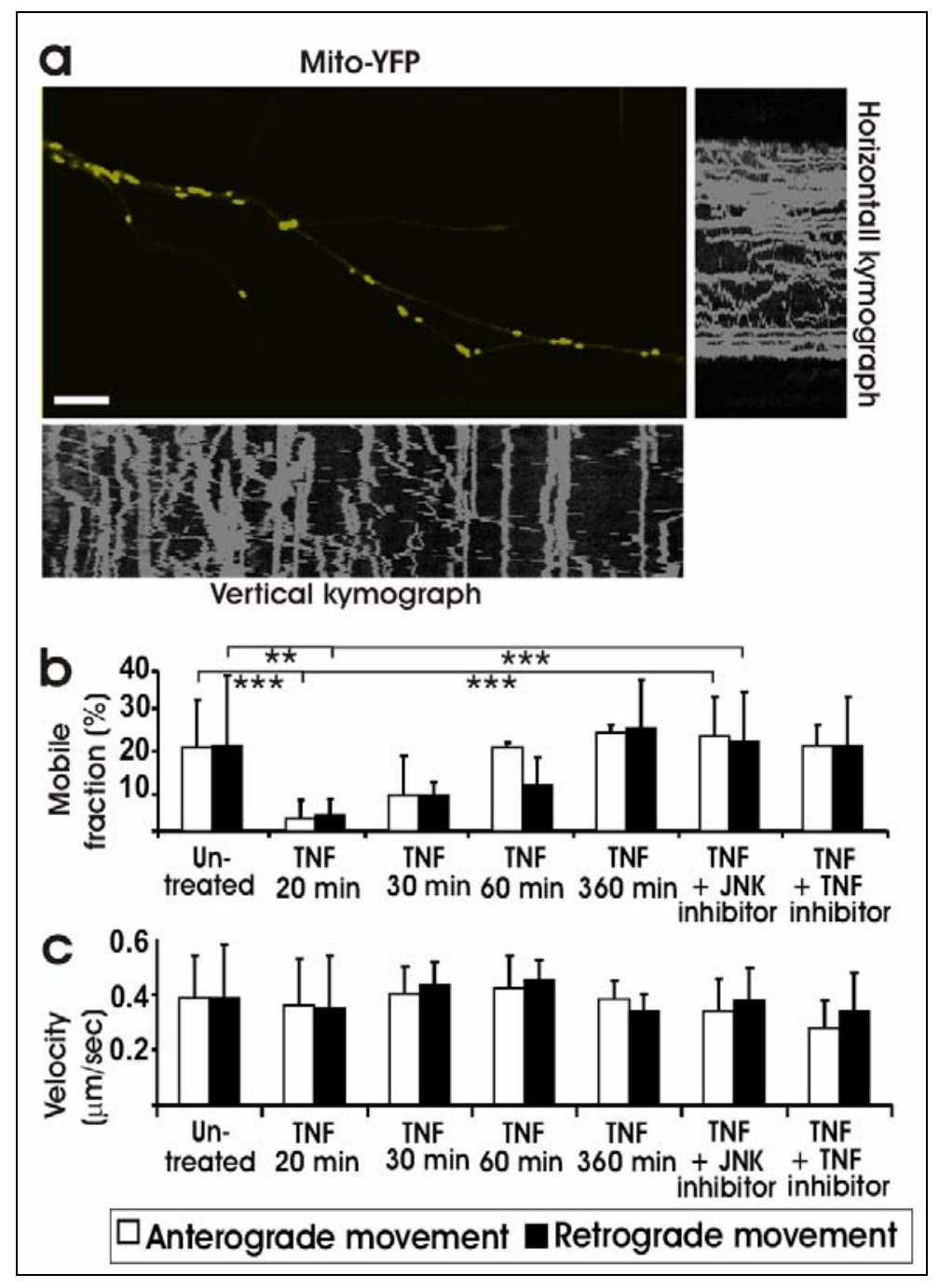

Fig 13. Inhibition of mitochondria movements by TNF- $\alpha$ via JNK. Cultured hippocampal neurons were transfected with a mitochondrial targeting sequence tagged to YFP (Mito-YFP) and scanned by time lapse confocal microscopy.

a. Images of mitochondrial movements were collected each 20 seconds and analyzed in the horizontal and vertical kymograph. The first image collected and the corresponding kymographs over 20 minutes are shown from a representative untreated axon. Scale bar: $10 \mu \mathrm{m}$.

b. The percentage of mitochondria moving along axons (mobile fraction) anterogradely and retrogradely was quantified in neurons transfected with a mitochondrial targeting sequence tagged to YFP. Treatment of neurons with TNF- $\alpha$ for 20 minutes reduced the mobile fraction. At 360 minutes after TNF- $\alpha$ treatment the movement of mitochondria reverted to normal levels. Effect of TNF- $\alpha$ on mitochondrial movement was neutralized by inhibition of JNK with SP600125 (JNK inhibitor). Furthermore, the effect of TNF- $\alpha$ on axonal mitochondria movement was inhibited by blocking TNF- $\alpha$ with a TNFRI-IgG-fusion protein (TNF inhibition). Data are presented as mean $+/-\mathrm{SD} . * * * \mathrm{p}<0.001 * * \mathrm{p}<0.01$ (Mann Whitney U test).

c. The velocity of mitochondria moving along axons anterogradely and retrogradely was quantified in neurons transfected with a mitochondrial targeting sequence tagged to YFP. No change in velocity was observed after treatment with TNF- $\alpha$ or combined treatment with TNF- $\alpha$ and JNK inhibitor. Data are presented as mean $+/-\mathrm{SD}$. 


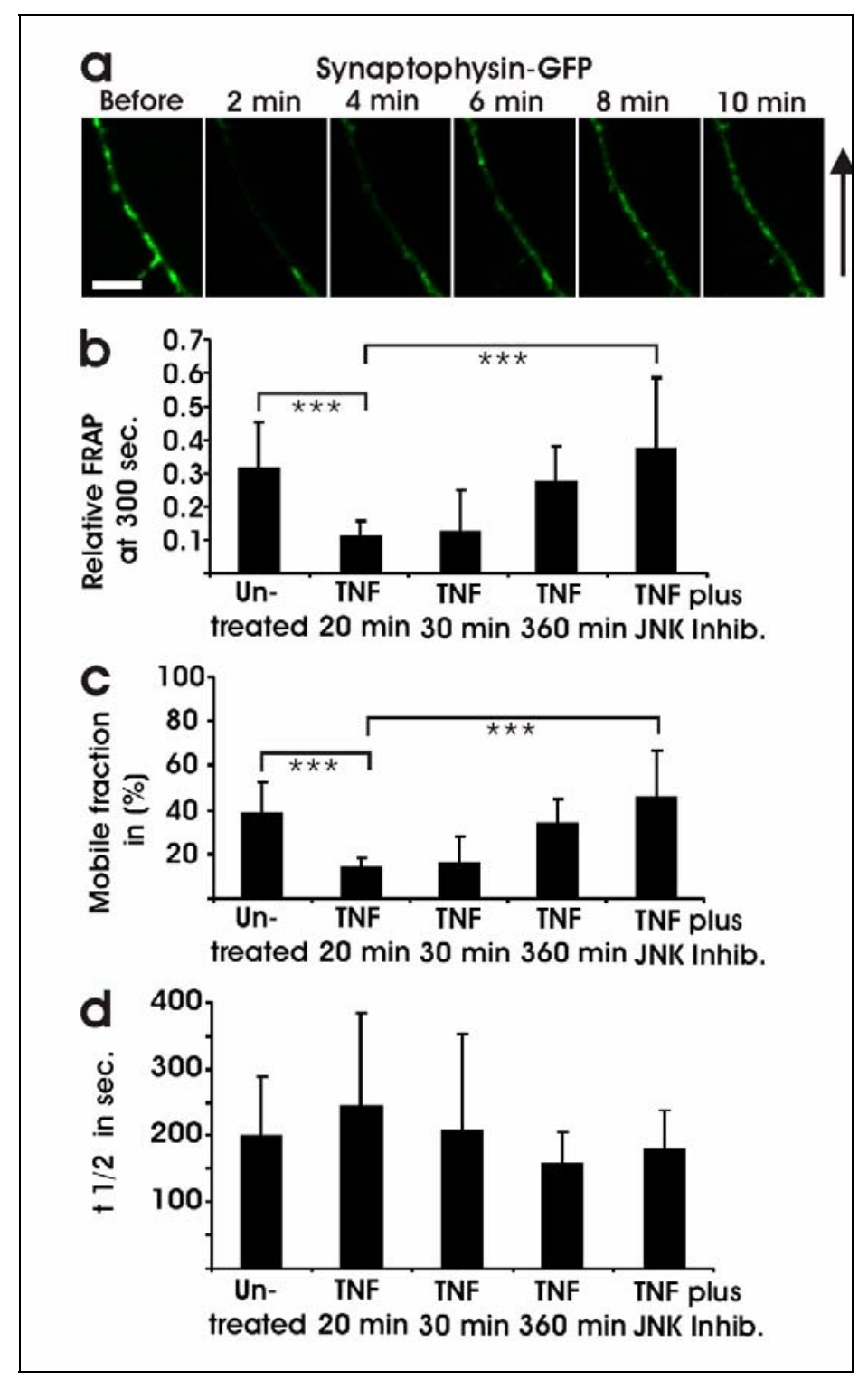

Fig 14. Inhibition of synaptophysin movements by TNF- $\alpha$ via JNK. Cultured hippocampal neurons were transfected with synaptophysin-GFP and scanned by FRAP confocal microscopy.

a. Images of synaptophysin-GFP movements were collected every 20 seconds after photobleaching of a 20 $\mu \mathrm{m}$ axonal segment. Selected images before bleaching and 2, 4, 6, 8 and 10 minutes after bleaching are shown. Scale bar: $7 \mu \mathrm{m}$.

b. Relative FRAP at 300 seconds in axons of neurons transfected with synaptophysin-GFP and treated with TNF- $\alpha$ or TNF- $\alpha$ plus JNK inhibitor. TNF- $\alpha$ treatment reduced the axonal transport of synaptophysin-GFP. The effect of TNF- $\alpha$ on synaptophysin-GFP transport was neutralized by JNK inhibition. Data are presented as mean $+/$ - SD. For each experimental condition $n>10 .{ }^{* * *} p<0.001$. (t test)

c. Mobile fraction of FRAP in axons of neurons transfected with synaptophysin-GFP. TNF- $\alpha$ treatment significantly reduced the percentage of synaptophysin-GFP moving along the axons. Data are presented as mean $+/$ - SD. For each experimental condition $n>10 . * * * p<0.001$. ( $t$ test)

d. Half-time value ( $\left.t_{1 / 2}\right)$ of FRAP in axons of neurons transfected with synaptophysin-GFP. No significant change in $t_{1}$ was observed after TNF- $\alpha$ treatment indicating that TNF- $\alpha$ does not modulate the velocity of the remaining synaptophysin-GFP moving along axons. Data are presented as mean +/- SD. For each experimental condition $\mathrm{n}>10$. 


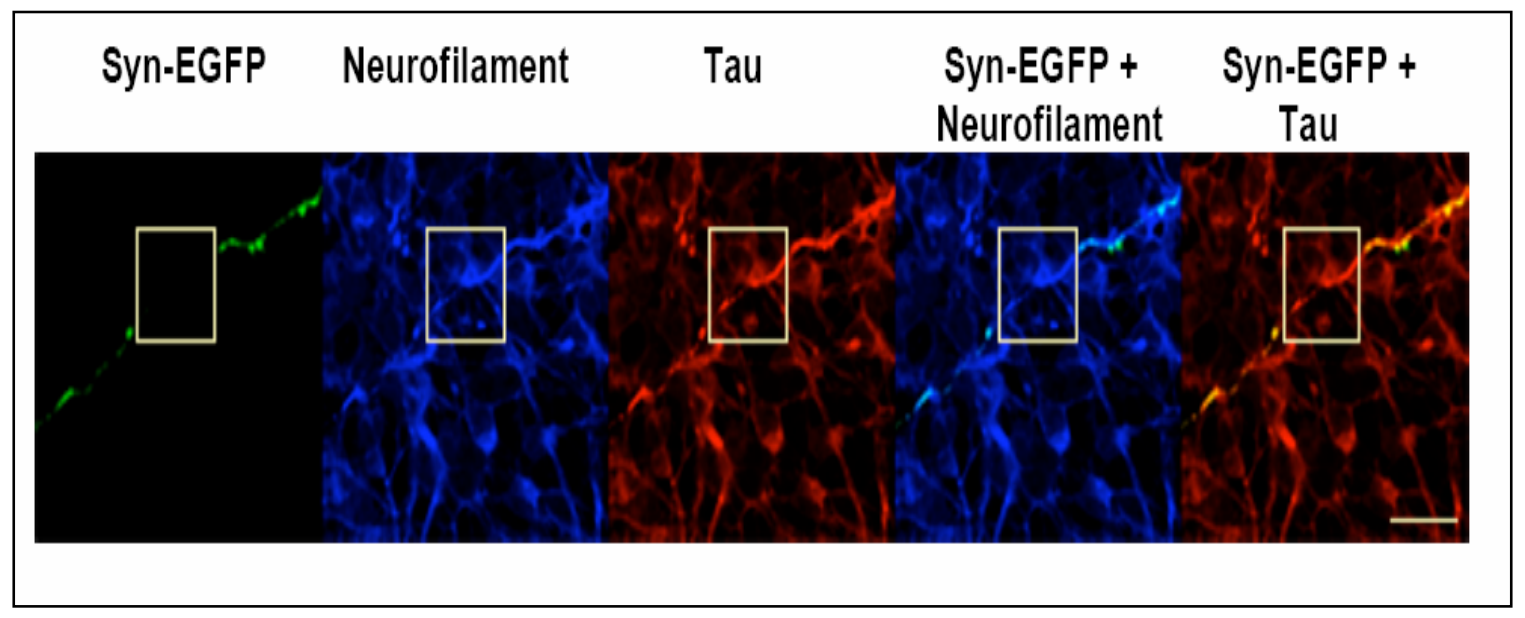

Fig 15. Immunohistochemistry for neurofilament and tau after FRAP analysis. Cultured hippocampal neurons were transfected with synaptophysin-EGFP (Syn-EGFP; green) and FRAP was performed at the axon (bleached area as indicated in the images). Neurons were fixed in immunolabeled with specific antibodies direct against neurofilament (blue) and tau (red). No difference in the immunolabelling of the cytoskeleton is detected between the bleached and unbleached areas of the axon, indicating that the photobleaching of synaptophysin-EGFP does not harm the axonal cytoskeleton. Scale bar: $20 \mu \mathrm{m}$. 
Relative FRAP at $300 \mathrm{sec}$ (mean +/- SD)

\begin{tabular}{cc}
\hline $\begin{array}{c}\text { First FRAP } \\
\text { measurement }\end{array}$ & $0.289+/-0.08$ \\
\hline $\begin{array}{l}\text { Second FRAP } \\
\text { measurement, } \\
\text { after } 24 \mathrm{~h} .\end{array}$ & $0.291+/-0.09$
\end{tabular}

Half time in sec. (mean $+/-$ SD)

\begin{tabular}{cc}
\hline $\begin{array}{c}\text { First FRAP } \\
\text { measurement }\end{array}$ & $174,8+/-78,6$ \\
\hline $\begin{array}{l}\text { Second FRAP } \\
\text { measurement, } \\
\text { after } 24 \mathrm{~h} .\end{array}$ & $180,9+/-60,9$ \\
\end{tabular}

Mobile fraction (mean $+/$ - SD)

\begin{tabular}{cc}
\hline $\begin{array}{c}\text { First FRAP } \\
\text { measurement }\end{array}$ & $0,46+/-0,10$ \\
\hline $\begin{array}{l}\text { Second FRAP } \\
\text { measurement, } \\
\text { after } 24 \mathrm{~h} .\end{array}$ & $0,46+/-0,08$ \\
\end{tabular}

Table: No change in axonal transport of synaptophysin-EGFP after re-analysis of the same neuron. Cultured hippocampal neurons were transfected with synaptophysinEGFP. Axons of transfected neurons were analyzed by fluorescence recovery after photobleaching (FRAP). After 24 hours the axons of the same neurons were identified and re-analyzed by FRAP. No significant difference (Man Whitney U-test, p > 0.8; $n=5$ ) was found for any measured parameter between the first and second FRAP analysis 24 hours later indicating that the photobleaching procedure does not cause damage to neurons. 


\begin{tabular}{cc}
\hline $\begin{array}{l}\text { DEA/NONOate } \\
\text { NO donor }(\mu \mathrm{M})\end{array}$ & $\begin{array}{c}\text { Neuronal survival after } 24 \text { hours of NO donor treatment in } \\
\text { relation to untreated cultures (mean }+/- \text { SEM) }\end{array}$ \\
\hline 100 & $0.98+/-0.05$ \\
\hline 200 & $1.01+/-0.03$ \\
\hline 300 & $0.97+/-0.02$ \\
\hline 400 & $0.96+/-0.04$ \\
\hline 500 & $0.94+/-0.08$ \\
\hline 600 & $0.79+/-0.15$ \\
\hline 1000 & $0.55+/-0.14$
\end{tabular}

Table: Levels of NO used in our experiments $(300 \mu \mathrm{M})$ do not cause cell death. Hippocampal neurons were treated with varying concentrations of NO donor, and assessed for survival 24hours after treatment. 


\section{APPENDIX 1 : Abbreviations}

APP Amyloid Precursor Protein

C57BL/6 Mice strain

CD Cluster of Differentiation

cGMP Cyclic guanosine monophosphate

DEA/NONAde Nitric Oxide Donor

EGFP Enhanced Green Fluorescence Protein

EYFP Enhanced Yellow Fluorescence Protein

FCS Fetal Calf Serum

FITC Fluoro-Isothiocyanate

FRAP Fluorescence Recovery After Photobleaching

FRET Föster Resonance Energy Transfert

GAPDH Glyseraldehyde-3-phosphate dehydrogenase

Ig Immuno Globuline

IL-betaInterleukin beta

INF-gamma Interferon gamma

iNOS Inducible Nitric Oxide Synthethase

JIP c-Jun N terminal Kinase Interaction Protein

JNK c-Jun $\mathrm{N}$ terminal Kinase

KIF1A Kinesin Motor Protein Family 1a

KIF5B Kinesin Motor Protein Family 5b

MAP2 Microtubule Associated Protein 2

NFKappaB Nuclear Factor Kappa-B,

NO Nitric Oxide

NOS Nitric Oxide Synthethase

p38 Synaptophysin

p65 Synaptotagmin

PBS Phosphate Buffered Saline

PCR Polymerase Chain Reaction

PMT PhotoMultiplier Tubes 
SP600125 Jun N-terminal kinase (JNK) inhibitor anthra[1,9-cd]pyrazol-6(2H)-one

TD-FLIM Time-domain Fluorescence lifetime imaging microscope

TNF-alpha Tumor Necrosis Factor Alpha

VAMP2 Vesicle-Associated Membrane Protein 2 


\title{
Appendix 2: Published papers
}

\section{J Neurosci. 2005 Jan 12;25(2):352-62. Breakdown of axonal synaptic vesicle precursor transport by microglial nitric oxide.}

\author{
Stagi M, Dittrich PS, Frank N, Iliev AI, Schwille P, Neumann H.
}

The mechanism of axonal injury in inflammatory brain diseases is still unclear. Increased microglial production of nitric oxide (NO) is a common early sign in neuroinflammatory diseases. We found by fluorescence correlation spectroscopy that synaptophysin tagged with enhanced green fluorescence protein (synaptophysin-EGFP) moves anterogradely in axons of cultured neurons. Activated microglia focally inhibited the axonal movement of synaptophysin-EGFP in a NO synthase-dependent manner. Direct application of a NO donor to neurons resulted in inhibition of axonal transport of synaptophysin-EGFP and synaptotagmin I tagged with EGFP, mediated via phosphorylation of c-jun NH2-terminal kinase (JNK).

Thus, overt production of reactive NO by activated microglia blocks the axonal transport of synaptic vesicle precursors via phosphorylation of JNK and could cause axonal and synaptic dysfunction.

Brain. 2005 Aug;128(Pt 8):1778-89. Epub 2005 Apr 27. LPS receptor (CD14): a receptor for phagocytosis of Alzheimer's amyloid peptide.

\author{
Liu Y, Stagi M, Walter S, Cherny D, Letiembre M, Schulz-Schaeffer W, Heine H, Penke \\ B, Neumann H, Fassbender K.
}

The amyloid beta peptide 42 (Abeta(42)) plays a key role in neurotoxicity in Alzheimer's disease. Mononuclear phagocytes, i.e. microglia, have the potential to clear Abeta by phagocytosis. Recently, the lipopolysaccharide (LPS) receptor CD14 was shown to mediate phagocytosis of bacterial components and furthermore to contribute to neuroinflammation in Alzheimer's disease. Here, we investigated whether this key innate immunity receptor can interact with Abeta(42) and mediate phagocytosis of this peptide. Using flow cytometry, confocal microscopy and two-photon fluorescence lifetime imaging (FLIM) combined with fluorescence resonance energy transfer (FRET), we demonstrated a direct molecular interaction in the range of a few nanometers between Abeta(42) and CD14 in human CD14-transfected Chinese hamster ovary cells. Investigations using cells that were genetically deficient for this receptor showed that in $<30$ minutes exogenous Abeta(42) added to cultured primary microglial cells was phagocytosed into the cytoplasmic compartment in a CD14-dependent manner. This phagocytosis occurred at Abeta(42) concentration ranges that were considerably lower than the threshold to activate a cellular inflammatory reaction. In contrast, there was no association of CD14 to microglial internalization of microbeads. In complementary clinical experiments, we detected a pronounced CD14 immunoreactivity on parenchymal microglia spatially correlated to characteristic Alzheimer's disease lesion sites in brain sections of Alzheimer's disease patients but not in brain sections of control subjects. By showing a close interaction between CD14 and Abeta(42), demonstrating a direct role of CD14 in Abeta(42) phagocytosis, and detecting CD14-specific staining in brains of Alzheimer's disease patients, our results indicate a role of the LPS receptor in the pathophysiology of Alzheimer's disease, which could be of therapeutic relevance. 
Submitted. JCB on Sept 2005.

\title{
Unloading kinesin transported axonal cargoes from the tubulin track via the inflammatory c-Jun $\mathrm{N}$-terminal kinase pathway
}

\author{
Stagi M, Gorlovoy P, Takahashi K and Neumann H
}

Axonal transport of mitochondria and synaptic vesicle precursors via kinesin motor protein is essential to keep integrity of axons and synapses. Disturbance of axonal transport is an early sign of neuroinflammatory and neurodegenerative diseases. Treatment of cultured neurons by the inflammatory cytokine tumor necrosis factor- $\alpha$ (TNF) stimulated phosphorylation of c-Jun N-terminal kinase (JNK) in axons. TNF treatment induced dissociation of the heavy chain kinesin family-5B (KIF5B) protein from tubulin in axons, but not cell bodies as determined by lifetime-based Förster resonance energy transfer (FRET) analysis. Dissociation of KIF5B from tubulin after TNF treatment was dependent on phosphorylation of JNK. Furthermore, TNF inhibited axonal transport of mitochondria and synaptophysin by reducing the mobile fraction via JNK. Thus, TNF produced by activated glial cells in inflammatory or degenerative neurological diseases acts on axons by breaking apart the kinesin-tubulin complex and inhibits axonal mitochondria and synaptophysin transport via phosphorylation of JNK.

Revised. Nat. Med. on Sept 2005.

\section{Repair Therapy of experimental autoimmune encephalomyelitis by TREM2- transduced myeloid cells}

\author{
Takahashi K, Prinz M, Stagi M, and Harald Neumann \\ In experimental models of multiple sclerosis, inflammation can successfully be prevented, while promoting \\ repair is still a major challenge for therapy. Bone marrow or blood-derived hematopoietic precursor cells \\ are suitable and easy accessible sources for cell-based repair therapies. Efficient removal of apoptotic cells \\ and cellular debris without inflammation during degenerative central nervous system (CNS) diseases is \\ essential for repair of the injured tissue and disease recovery 1,2. Recently we discovered that the \\ microglial triggering receptor expressed on myeloid cells-2 (TREM2) stimulates phagocytosis and down- \\ regulates inflammatory signals in microglia 3 . Here we show that intravenous cell therapy by TREM2- \\ transduced myeloid cells at the disease peak of experimental autoimmune encephalomyelitis (EAE) leads to \\ a significant amelioration of clinical symptoms, reduction in axonal damage and prevention of \\ demyelination. After intravenous application, the TREM2-transduced myeloid cells migrated into the \\ inflammatory spinal cord lesions within 2 hours, showed increased phagocytosis and created an anti- \\ inflammatory cytokine milieu within the spinal cord. The TREM2 expressing myeloid cells shut off \\ negative cycles of inflammation by removing cellular debris and creating a milieu supportive for repair of \\ injured tissue. Thus, we identified TREM2 as a novel target for the ex vivo cell therapy of inflammatory \\ autoimmune brain diseases.
}




\section{Appendix 3: CV}

\section{MASSIMILIANO STAGI}

\section{Curriculum vitae}

- DATE AND PLACE OF BIRTH: $29^{\text {th }}$ August 1973, Montevarchi (Arezzo - Italy)

- ADDRESS: Via Aldo Moro, 7

52025 Montevarchi (Arezzo - Italy)

Tel. +390559103312

E-mail: mstagi@gwdg.de ; massimiliano.stagi@uni-bonn.de

Current Institute: Life and Brain (Bonn)

- MARITAL STATUS: Single

- EDUCATION:

- 1994: High School Diploma (biologically oriented) at the Galilei Institute of Arezzo (Italy).

Evaluation 60/60 (A+)

- 1994-2000: Diploma Degree in Biology at the University of Florence (Italy) with dissertation on a genetics-ethological subject, made in collaboration with the RICE University (Houston, Texas). Evaluation 108/110 (A)

- 2001: Technical Diploma in meteorology, obtained as Italian Air Force Officer. Evaluation 27.5/30 (A)

- 2002: Enrolment in Biological List (Requirement in Italy to practise as a professional biologist) 150/150 (A+)

- 2002 - until present: PhD student in neuroimmunology focusing on axonal transport in neural pathologies Supervisor, Neuroimmunology: Dr. Harald Neumann. Co-supervisor, Neurobiology: Prof. Ralf Heinrich.

Co-supervisor, Membrane Biophysics: Prof. Erwin Neher.

- PUBLICATIONS:

Stagi, M., Dittrich, P.S., Frank, N., Iliev, A.I., Schwille, P., Neumann, H. Breakdown of axonal synaptic vesicle precursor transport by microglial nitric oxide, J. Neurosci.

Liu Y, Stagi M, Walter S, Cherny D, Letiembre M, Schulz-Schaeffer W, Heine H, Penke B, Neumann H, Fassbender K. LPS receptor (CD14): a receptor for phagocytosis of Alzheimer's amyloid peptide. Brain.

- POSTERS: 
- VI. European meeting on glial function in health and disease, Berlin, 3-6 Sept, 2003

- $\quad 7^{\text {th }}$ International Congress of Neuroimmunology, Venice, Italy, 28-Sept 2-Oct 2004

- Interdisciplinary PhD Student Symposium on Current Topics in the Neurosciences, Goettingen, Germany, November 12 - 14, 2004.

- WORK EXPERIENCE:

- Sept. 2000/Nov. 2001: Service as Italian Air Force $2^{\text {nd }}$ Lieutenant, developing dataprocessing software for the study of atmospheric gasses. Carried out in the Observatory of Mount Cimone (Modena - Italy)

- 2002-2003: Tutor for the Max Planck Neuroscience Program in Protein synthesis, Basic immunology, and Axonal transport.

- LAB EXPERIENCE:

- Molecular biology and cloning.

- Use of lentiviral vectors in cell lines and neurons.

- Plasmid transfection of cell culture.

- Primary neuronal culture.

- Neuronal slice culture.

- Immunocytochemistry.

- Two-photon laser, confocal, FLIM, FRET,FRAP.

- COMPUTER KNOWLEDGE:

- Operating Systems: MS-DOS

Windows

Linux Mandrake

MacOs

- Software: Microsoft Office (full package)

Mathematica

Mathlab

Mathcad

- Languages: Visual Basic 6.0

Java 1.3 (elements)

HTML

- Bioinformatic programs: GCG, EMBOSS, STADEM

- METHODOLOGY COURSES:

- Methoden und Werkzeuge der Sequenzanalyse: GCG , EMBOSS, STADEM. Gottingen GWDG.

- 3rd Workshop on FRET FLIM and Advanced 2-Photon Microscopy by LaVisionBIOTEC

- Advance workshop on MatLab for FLIM application. Gottingen GWDG. 


\section{Acknowledgements}

I would like to thank Prof. Dr. Harald Neumann for giving me the opportunity to work in his laboratory on a really interesting project which stimulated me and lead me to learn new and interesting techniques.

I am also extremely obligated to Prof. Ralf Heinrich for his total assistance whatever and whenever I needed it. I am also appreciative of Prof. Erwin Neher for his support as my thesis commission.

I am very grateful to Laura Swan for reading this thesis and for her continuous support.

I would also like to thank Ms. Dagmar Thomitzek and Ms. Wiebke Heinrich for all support in administrative matters but especially for their friendship.

I never will forget the hard work and cooperation of Nadja Frank and her high professionalism. Many thanks also to lab of Petra Schwille and Petra S. Dittrich.

Thank to Heiko Rhöse for molecular biology support. Thank to Alexandra Bohl for neuronal culture. Thank to Kazuya Takahashi for help on biochemistry. Thank to Alessandro Esposito for interesting and always useful discussions about FLIM and FRET.

And a big expression of gratitude to everyone in the ENI, especially those in the Neuroimmunology group, good friends and colleagues at the same time. 
"Sulla difficolta' della ricerca.

Io ho disfatto piu di dieci corpi umani, sminuzzando tutta la carne che si trovava intorno alle vene, per metterle a nudo e poterle disegnare; e per ottenere questi disegni non basta l'amore per la ricerca, perche' tu potresti essere impedito dallo stomaco, dalla ripugnanza o potresti essere impedito dalla paura con l'abitare di notte in compagnia di morti squartati e scorticati, spaventosi a vedersi, e se questo non ti impedisce forse $t i$ manchera' la sapienza del disegno"',

\section{(Leonardo Da Vinci, 1452)}

"On the difficulties of research.

I have destroyed more than ten human bodies, hashed all that meat around the veins, to strip them naked so as to draw them. To obtain these drawings, it is not enough to love research, as you maybe hindered by weakness of stomach, 6y repugnance, or you may fear to work nights in the company of the flayed and quartered dead, terrible to see. And if all this does not impede you, you may yet lack the talent to draw." (Leonardo Da Vinci, 1452) 